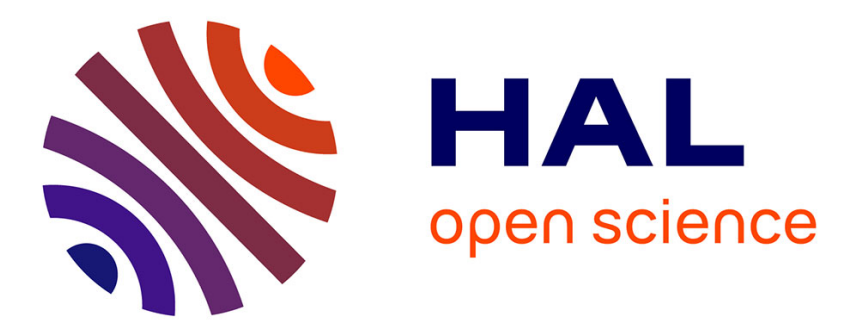

\title{
Experimental analysis of temperature field and distortions in multi-pass welding of stainless cladded steel
}

Rami Ghorbel, Ahmed Ktari, Nader Haddar

\section{- To cite this version:}

Rami Ghorbel, Ahmed Ktari, Nader Haddar. Experimental analysis of temperature field and distortions in multi-pass welding of stainless cladded steel. International Journal of Advanced Manufacturing Technology, 2021, 113 (11-12), pp.3525-3542. 10.1007/s00170-021-06788-y . hal-03197025

\section{HAL Id: hal-03197025 \\ https://hal.science/hal-03197025}

Submitted on 17 Jun 2021

HAL is a multi-disciplinary open access archive for the deposit and dissemination of scientific research documents, whether they are published or not. The documents may come from teaching and research institutions in France or abroad, or from public or private research centers.
L'archive ouverte pluridisciplinaire HAL, est destinée au dépôt et à la diffusion de documents scientifiques de niveau recherche, publiés ou non, émanant des établissements d'enseignement et de recherche français ou étrangers, des laboratoires publics ou privés. 


\title{
Experimental analysis of temperature field and distortions in multi-pass welding of stainless cladded steel
}

\author{
Rami Ghorbel $^{1} \cdot$ Ahmed Ktari $^{1,2} \cdot$ Nader Haddar $^{1}$
}

\begin{abstract}
The stainless clad steel materials (particularly A283-Gr-C hot-rolled to austenitic stainless steel plate SA240 TP 316L) have become widely used in the fabrication of heat exchangers, pressure vessels, and other components owing to their very interesting properties and low production cost. These cladded materials are mostly joined using multi-pass welding techniques. The temperature distribution that supervenes during welding affects the microstructures and the mechanical properties and may generate residual stresses in the heat-affected zone of the welded plates. Since limited experimental data are available in the literature regarding the complex cases of multi-pass welding of cladded steel materials, a thorough experimental study was performed in order to evaluate the temperature distribution on the welded plates. In fact, eight K-type thermocouples were fixed at different distances from the weld centerline in order to record the temperature evolution along longitudinal, transversal, and thickness directions during the welding process. Due to the unavoidable effects of the generated heat fluxes that always follow the welding, several dimensional changes were occurred on the welded plates. In this study, the longitudinal shrinkage and the angular distortion generated during the welding process by the effect of the heat fluxes were investigated. Then, tensile and bending tests were performed in order to check the welded plate reliability. It was found that (i) the welded joint presents a higher mechanical tensile strength than the parent metal and (ii) no separations, fractures, or tearing appear on the weld joint surface after the bending test.
\end{abstract}

\section{Introduction}

In recent years, there has been a spate of interest in the development of new materials, which exhibit better properties than the existing ones, and can be used in industrial applications at a reduced cost. Known as «cladded steel», these new materials were provided by joining different materials together using specific methods. Different methods of bonding clad materials have been industrialized. Kaya and Kahraman [1], for instance, investigated the explosive cladding, while
Venkateswara Rao et al. [2] studied the weld overlay cladding. In other studies, Khodadad et al. [3] worked on the roll bonding, whereas Ganesh.al [4] investigated the laser cladding. Taken together, these bi-materials exhibit a good corrosion resistance, good environmental stability, high specific resistance, and low production cost. Although each bonding method has its own advantages, the hot-roll technique seems to be the most commonly used process in the industries due to its large productivity, effective cost, and efficiency. This is can be confirmed by the work achieved by Flahaut. [5]. The most commonly fabricated hot-roll cladded steel sheets are $\mathrm{Al} /$ 304L [6], Fe/Ni alloy [7], and carbon steel/ stainless steel [3, 8]. Lately, since the hot-rolled clad plates seem to be the most economical solution to build pressure vessels [5], heat exchangers, and vessels reactors, considerable efforts have been made to develop carbon steel/stainless steel-clad material, which combined the already mentioned best properties to a reduced cost.

The welding of the stainless clad steel material is the most suitable joining method used in the industries. Several 
welding processes, such as shielded metal arc welding (SMAW) [9, 10], gas tungsten active welding (GTAW) [9-11], submerged arc welding (SAW) [12], laser welding [13], and gas metal arc welding (GMAW) [11], are used in the welding of the stainless steel cladded plates. All these processes are convenient to satisfy the corrosion resistance and mechanical properties requirements. However, the welding of the stainless clad material may meet several challenges and the welding difficulties relating to the welding process of the stainless clad steel plate need to be taken into account. To start with, the clad layer and the substrate have many differences in physical and mechanical properties, such as thermal expansion coefficient and heat conductivity. The difference in properties may lead to the formation of a high residual thermal stress at the welding clad interface during the welding and cooling processes $[14,15]$. In addition, a clear variation in chemical composition is often present between the clad layer and the substrate. Alloy elements (i.e., $\mathrm{Cr}$ and $\mathrm{Ni}$ ) in the clad layer can easily dilute and diffuse into the carbon steel welded bead, leading to low contents of alloy elements and a low corrosion resistance of the clad layer [2]. Furthermore, excessive diffusion of alloying elements can result in the formation of $\mathrm{Cr}_{23} \mathrm{C}_{6}$ carbides, leading to a severe intergranular depletion (Cr-depletion) and intergranular cracks [16]. Moreover, Wang et al. [17] reported in their work that a decarburized layer and a carbon rich layer were also found in the welding interface due to the easily dilution and the carbon diffusion.

In addition, during the joining process, the heat produced by the welding would influence the mechanical properties of each material making the cladded steel. Several researchers studied the joining method as well as the mechanical behavior and distortions generated by the multi-pass welding of the stainless clad steel. Park and Lee [18] have studied the mechanical properties and sensitivity of carbon steel A516 Gr 70 cladded to stainless steel A316. Itsuro et al. [19] investigated the distortion of the austenitic stainless clad steel. They reported that the formation of shrinkage and distortion were due to the welding process of the mild steel. They also reported that after welding, distortion was observed on the mild steel due to the amount of weld metal deposited at the mild steel side.

In view of the above discussion, it is clear that limited experimental data were found in literature regarding the temperature distribution and its effect on the bi-material distortions in the case of complex multi-pass welding of the cladded steel materials. In this context, an industrial case was proposed by SOCOMENIN company in order to study the effect of the welding process on the stainless cladded steel A240 TP 316L hot-rolled to A283 Gr C. In fact, building tanks dedicated to hydrochloric acid conditioning requires the use of a thick material with a good corrosion resistance. Considering these requirements, the company thought of using a thin layer of stainless steel hot-rolled to thick low carbon steel instead of a thick stainless steel material, as it would be a cheaper solution. Because of the dearth of information regarding the temperature evolution during multi-pass welding of the cladded steel and its effect on the studied bimaterials, and in order to evaluate the integrity of the welded joint, the present paper aims to (i) study the evolution of the temperature distribution during the multi-pass welding process on the stainless clad steel plates, (ii) investigate the dimensional changes of the welded plates generated by the effect of the heat fluxes during the welding process, and (iii) examine the tensile and bend mechanical properties of the welded joint in order to confirm the welding reliability.

\section{Experiment setup}

Two plates with dimensions of $200 \mathrm{~mm} \times 400 \mathrm{~mm}$ were extracted from a cladded sheet metal obtained by hot-roll bonding. This bi-material consists of a $12 \mathrm{~mm}$ low carbon steel as a base metal (A $283 \mathrm{Gr} \mathrm{C}$ ) and a $3 \mathrm{~mm}$ austenitic stainless steel as a clad layer (A 240 TP 316L). The typical chemical composition of the clad material is given in Table 1. Before the welding process, the preparation of the joints seems to be mandatory to fuse the entire faces of the two materials. Thence, the plates were fitted up by chamfering a UV-groove joint between them. Then, they are tacked together at both ends with a uniform gap of $3 \mathrm{~mm}$ according to the industrial practice code $A S M E$ Section $I X Q W-402$ [20]. Actually, the function of the root gap and root face are, respectively, to allow penetration and remove heat excess as it acts like a heat sink. Figure 1a and $\mathrm{b}$ display all the geometrical and dimensional details of the joint configuration. Three strongbacks are tacked on the plates to ensure their uniform alignment (Fig. 1c).
Table 1 Typical chemical composition of clad steel plates and filler metals used in the experiments (wt. \%)

\begin{tabular}{llllllllll}
\hline & Elements & $\mathrm{C}$ & $\mathrm{Si}$ & $\mathrm{Mn}$ & $\mathrm{P}$ & $\mathrm{S}$ & $\mathrm{Cr}$ & $\mathrm{Ni}$ & $\mathrm{Mo}$ \\
\hline Base material & A283 Gr C & 0.167 & 0.172 & 0.479 & 0.019 & 0.022 & - & - & - \\
& A240 TP 316 & 0.017 & 0.514 & 1.124 & 0.038 & 0.002 & 16.654 & 10.109 & 2.092 \\
Filler metals & ER 316L & 0.08 & 0.53 & 1.17 & 0.053 & 0.008 & 16.18 & 10.55 & 1.90 \\
& E7018 & 0.23 & 0.171 & 0.402 & 0.032 & 0.012 & 0.024 & 0.021 & $<0.002$ \\
& ER 309L & 0.025 & 0.45 & 1.8 & 0.02 & 0.02 & 24 & 13 & - \\
\hline
\end{tabular}


Fig. 1 Clad steel plates fitting up operation. a Butt-weld U-V joint dimensions; b Butt weld U-V joint configuration; $\mathbf{c}$ Tacking strongbacks

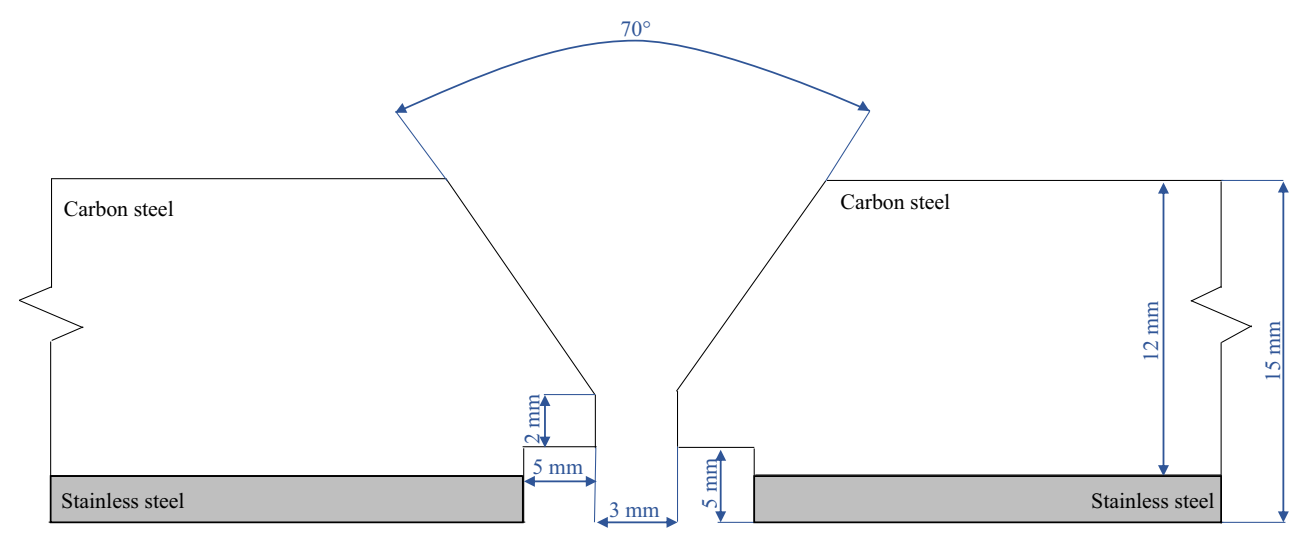

a

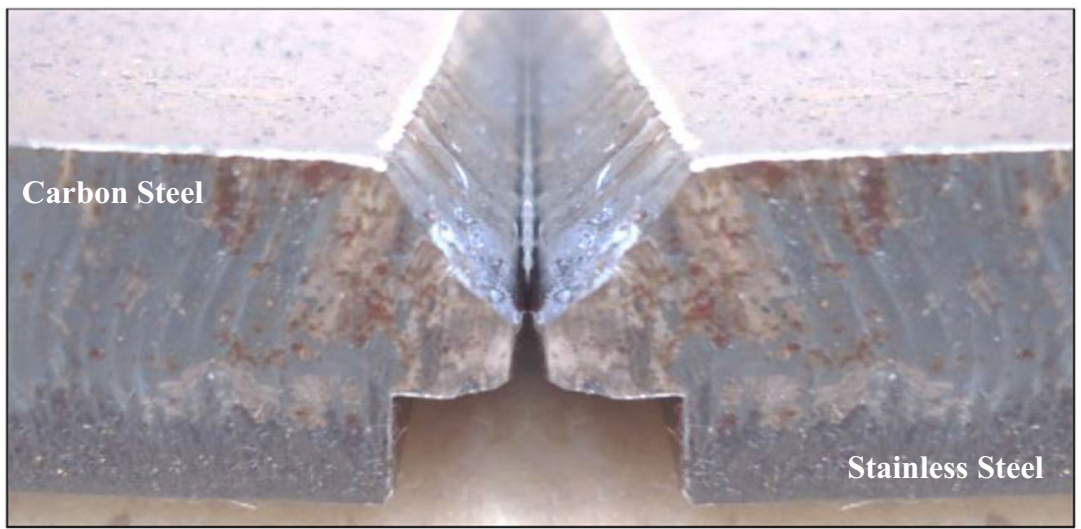

b

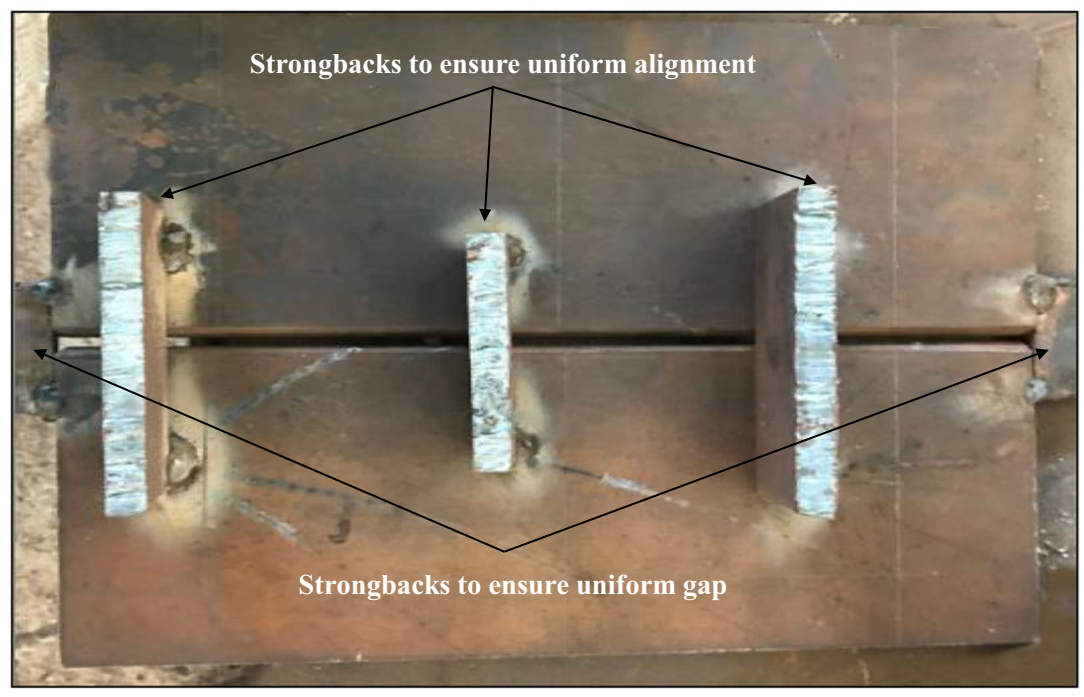

C
In this case study, the SMAW and the GTAW were the two welding processes selected for joining the carbon steel and stainless steel, respectively. Actually, the A283 Gr C carbon steel substrate has an excellent welding performance and a mature welding technology. It can be welded by various welding methods, such as GMAW, SMAW, and SAW. Herein, SMAW process was used thanks to its high productivity and its low production cost. Meanwhile, the SA 240 type $316 \mathrm{~L}$ clad layer has a larger thermal expansion coefficient and a smaller thermal conductivity compared to the substrate. In order to reduce the residual stresses of the welded joint, An et al. [11] have shown that both GTAW and GMAW processes can be selected.

In addition, these authors also showed that GTAW process was the most suitable for welding clad layer since it is characterized by a low dilution rate and low current [11]. In this 
context, a comparative study was performed by Kumar et al. [21] to investigate the effect of both welding processes on the mechanical properties of the welded stainless steel $316 \mathrm{~L}$ plates. These authors proved that the welded joint performed by GTAW process exhibits better mechanical properties compared to the welded joint performed by GMAW process. For this reason, the GTAW process was selected in this study to weld the clad layer of the bi-material plates.

Depending on the materials to be welded, atmospheric gases such as nitrogen, oxygen, carbon dioxide, and water vapor may reduce the weld quality. Hence, an external pure argon was used with a flow rate of $13 \mathrm{l} / \mathrm{min}$ on GTAW process in order to surround and protect the weld, whereas the SMAW process provides its own shielding system via a slag coverage using the flux coating electrode.

Welding was carried out in uphill position (3G). Threefiller metals E7018, ER316L, and ER309L were chosen according to ASM International Handbook Vol.06 [22] and AWS Standards (AWS B2.1-1-016-94R [23] and AWS B2.18-024 [24]) to weld the low carbon steel (A283 Gr C), austenitic stainless steel (SA 240 type 316L), and the transition zone, respectively. Typical chemical compositions of these filler metals are mentioned in Table 1. It is noted that E7018 was baked at $350{ }^{\circ} \mathrm{C}$ for 1 hour and then preserved in a holding oven at $150{ }^{\circ} \mathrm{C}$, in heated quiver, before being issued to the welder. The purpose of this conservation is to ensure that they are adequately dry before launching on the welding process.

The welding was carried out in accordance with ASME Section IX [20]. Nine passes were performed as follows: Three passes on the carbon steel side were performed using the SMAW process, whereas two passes in a transition phase and four passes on the stainless steel side using both GTAW process. Figure 2 illustrates the schematic view of welding bead layers on hot-rolled cladding steel. Since SMAW and GTAW are basically manual processes, the welder's skill seems to be important to achieve a good welded bead. A qualified welder was therefore selected to perform the welding process. Filler metals were consumed during welding process. Consequently, the replacement of the consumed electrode is required. Cleaning the welding area from slags and impurities seems to be mandatory for each filler metal replacement to get a homogeneous defect-free welded bead. This operation occurred from one pass to another and before starting the next bead as well. The root (first) pass weld, on carbon steel side, was carried out using Ø2.5 mm electrode. Grinding operation for weld recovery and strongbacks removal were performed during this pass. On the same steel side, the filling and covering (i.e., last pass on the carbon steel side) passes were carried out using $\varnothing 3.2 \mathrm{~mm}$ electrode. Filling and covering passes were carried out using $\varnothing 2.4 \mathrm{~mm}$ electrode on the stainless steel side.

In the case of multi-pass welding, the interlayer cooling time is an important factor that reduces the heat accumulation and decreases consequently the distortion of the coupon test. Lee et al. [25] and Bandari et al. [26] proved that reducing in cooling time between deposited layers may reduce the distortion. Nevertheless, this fact cannot be applied in the case of the austenitic stainless steel since they possess relatively a low thermal conductivity compared to the carbon steel. Actually, a short interlayer cooling time lead to a low dissipation of the accumulated heat in the welded joint that can result more distortion on the welded joint and can also affect the microstructure (formation of chromium carbide at grain interface). In this context, Bandari et al. [26] and Fessler et al. [27] reported that increasing the interlayer cooling time for the austenitic stainless steels and the nickel-base INVAR alloys decreases the distortion in the welded coupon. For this reason, in order to reduce the distortion and to avoid the presence of carbide in the vicinity of the welded joint, a cooling time was allowed after each pass according to the industrial codes [20, 28, 29]; i.e., the subsequent pass can be initiate only when the highest temperature of the welded joint reaches $150{ }^{\circ} \mathrm{C}$ (inter-pass temperature). In this study, the inter-pass temperature was controlled using infrared thermometer Fluke $₫ 566$. In addition, due to the absence of a seam tracking system, all welding steps were supervised and controlled by a CSWIP welding inspector in order to ensure a good quality of the welded joint.

During each pass, the voltage $(U)$ and current $(I)$ were measured during the welding process using a voltmeter and
Fig. 2 Schematic view of different passes after the welding process on hot-roll cladding steel

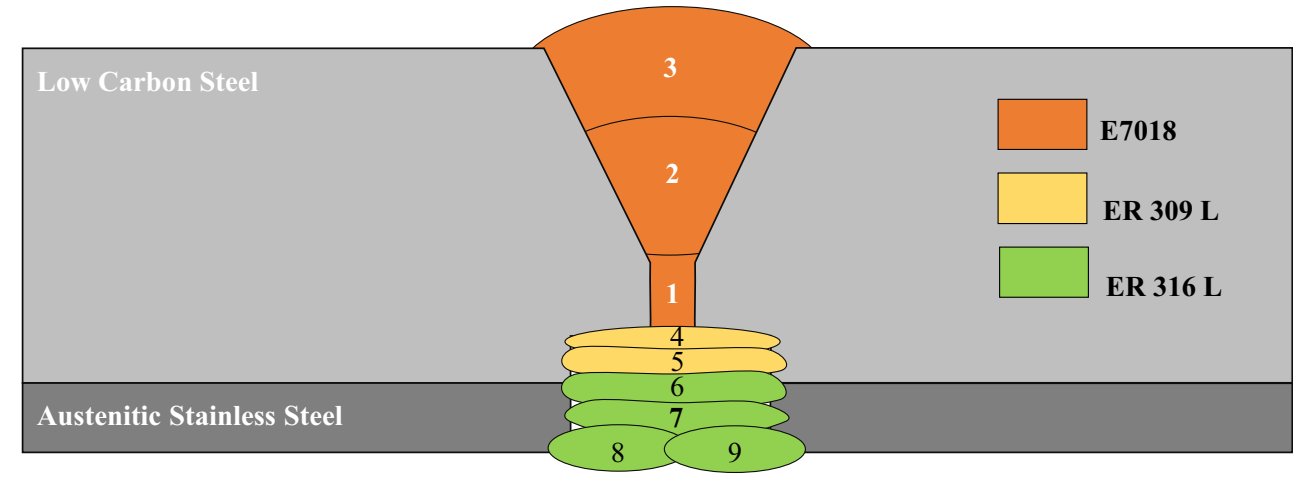


Table 2 Welding parameters used in the multi-pass welding process

\begin{tabular}{|c|c|c|c|c|c|c|c|}
\hline Number of passes & Filler metal & Filler metal Ø (mm) & Current \& polarity & Current (A) & Voltage (V) & Welding speed $(\mathrm{mm} / \mathrm{sec})$ & Heat input $(\mathrm{KJ} / \mathrm{mm})$ \\
\hline 1 & E7018 & 2.5 & DCRP* & 85 & 22 & 1.43 & 1.31 \\
\hline 2 & E7018 & 3.2 & DCRP & 116 & 22 & 1.13 & 2.27 \\
\hline 3 & E7018 & 3.2 & DCRP & 113 & 24 & 1.86 & 1.46 \\
\hline 4 & ER309 L & 2.4 & DCSP** & 133 & 10 & 1.3 & 1.02 \\
\hline 5 & ER309 L & 2.4 & DCSP & 141 & 11 & 1.18 & 1.31 \\
\hline 6 & ER316 L & 2.4 & DCSP & 142 & 11 & 1.1 & 1.42 \\
\hline 7 & ER316 L & 2.4 & DCSP & 140 & 11 & 0.93 & 1.66 \\
\hline 8 & ER316 L & 2.4 & DCSP & 130 & 10 & 1.25 & 1.04 \\
\hline 9 & ER316 L & 2.4 & DCSP & 133 & 10 & 0.86 & 1.55 \\
\hline
\end{tabular}

${ }^{*} D C R P$ direct current reverse polarity. ${ }^{* *} D C S P$ direct current straight polarity

an ammeter connected to the weld circuit. The welding duration was recorded for each pass, and the welding speed was calculated $(v)$ using the following relationship (Eq. (1)):

$v=$ average (welded distances/times)

All these parameters lead to calculate the heat input using the following formula (Eq. (2)):

$H I=(U \times I \times 60 / 1000 \times v)$

Depending on the welding process and the filler metal diameter, the voltage and the current were fixed with the ranges defined by the manufacture datasheet. The welding parameters during each pass are given in Table 2.

Eight K-type (chromel-alumel) thermocouples, with $\varnothing$ $6 \mathrm{~mm}$ and a standard accuracy of $\pm 2.2^{\circ} \mathrm{C}$ [30], were used to measure the transient temperature distribution during welding. These thermocouples are positioned as shown in Fig. 3 in such a way that the temperatures' evolution at the different directions (longitudinal, transversal, and thickness) could be recorded. For this reason, eight parts with dimension of $13 \mathrm{~mm} \times 25 \mathrm{~mm} \times 10 \mathrm{~mm}$ were drilled and threaded and then were placed and spot welded on the test coupon plate. The thermocouples were placed in each threaded hole and fixed by bolts. Figure 4 displays the attachment of the thermocouples on the test coupon. Then, those thermocouples are connected to an acquisition card DaqPro® in order to measure the temperature evolution during the welding. The temperature readings are useful to track the evolution of the temperature versus time.

In order to evaluate the welded joint performance, a preliminary study of the mechanical properties, i.e., tensile and

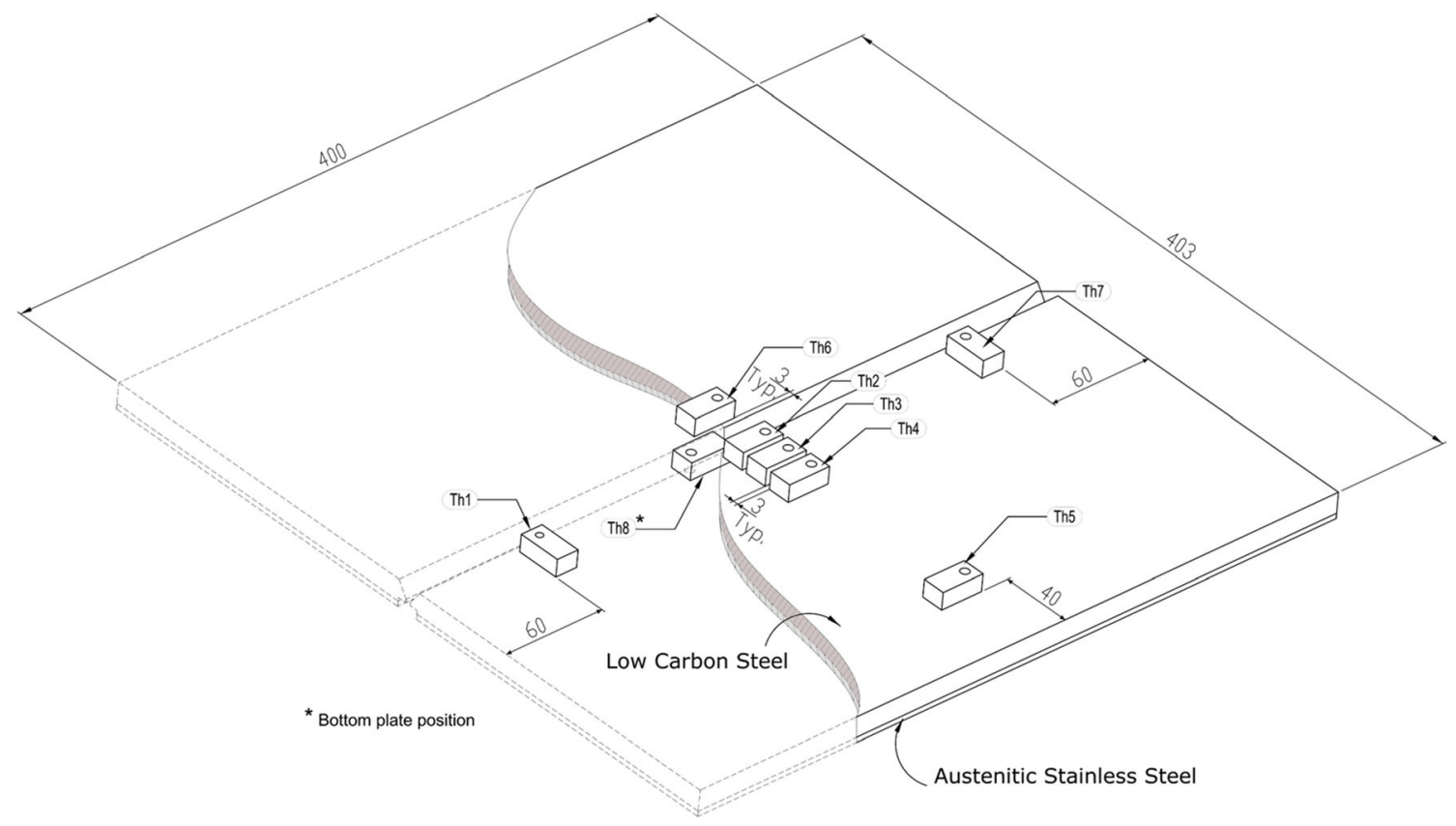

Fig. 3 Dimensional details and thermocouples location to monitor temperature variation 


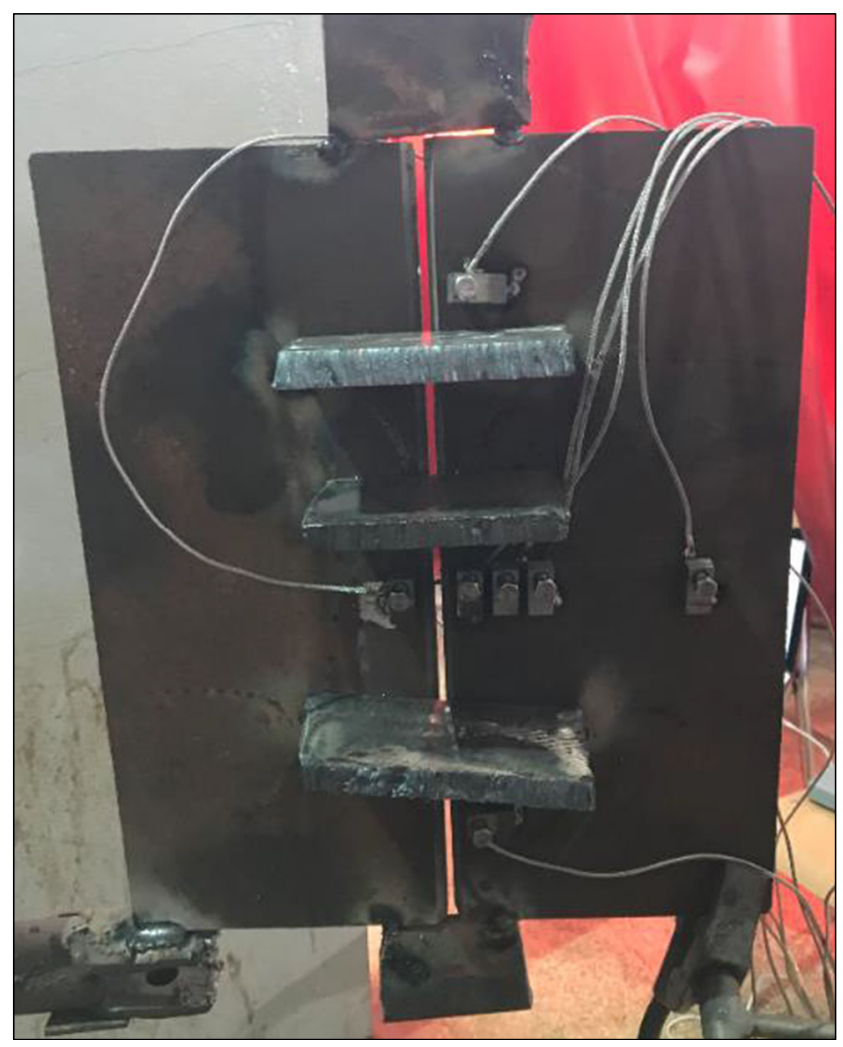

Fig. 4 Thermocouples' attachment on the test coupon

bend tests, was carried out. Transversal tensile specimens were extracted from the test coupon and were prepared according to the ASME IX [20] in order to evaluate the transverse tensile properties. All dimensional details are illustrated in Fig. 5. Tensile tests were carried out at room temperature using universal testing machine (UTM®) with a capacity of $300 \mathrm{kN}$. Experiments were conducted with a crosshead speed of $10 \mathrm{~mm} / \mathrm{min}$. In addition, four side bend test specimens were prepared according to the ASME IX [20] in order to determine the degree of soundness and ductility of the welded joint. All dimensional details are displayed in Fig. 6. The bend specimens were placed in three-point bend universal testing machine. The distance between the two bottom rollers was fixed at $60 \mathrm{~mm}$, and the top roller is centered in the middle of the bend specimens welded area. During the experiment, the specimens were side bent till $180^{\circ}$, and then, bent surfaces were evaluated.

\section{Results and discussion}

In this experimental study, the welding was performed according to the experiment setup described above. Upon achieving the thermal cycle, three metallurgical zones were observed in the plate: the base metal zone (BM), the heat-affected zone (HAZ), and the welded metal zone (WM). The macroscopic cross section, displayed in Fig. 7, illustrates the three metallurgical zones.

In a single pass welding, the peak temperature and the cooling rates that follow the heating determine the HAZ structure, while the thermal gradient, solidification rate, and cooling rate at the boundary (liquid-solid) determine the WM zone solidification structure. The HAZ can be divided into a number of sub-zones (coarse grain, fine grain, and intercritical grain).

The microstructure types and width of the sub-zones are determined by the heating and cooling cycles due to the thermal properties of the material and the arc movement. In a multi-pass welding, the HAZ microstructure evolution
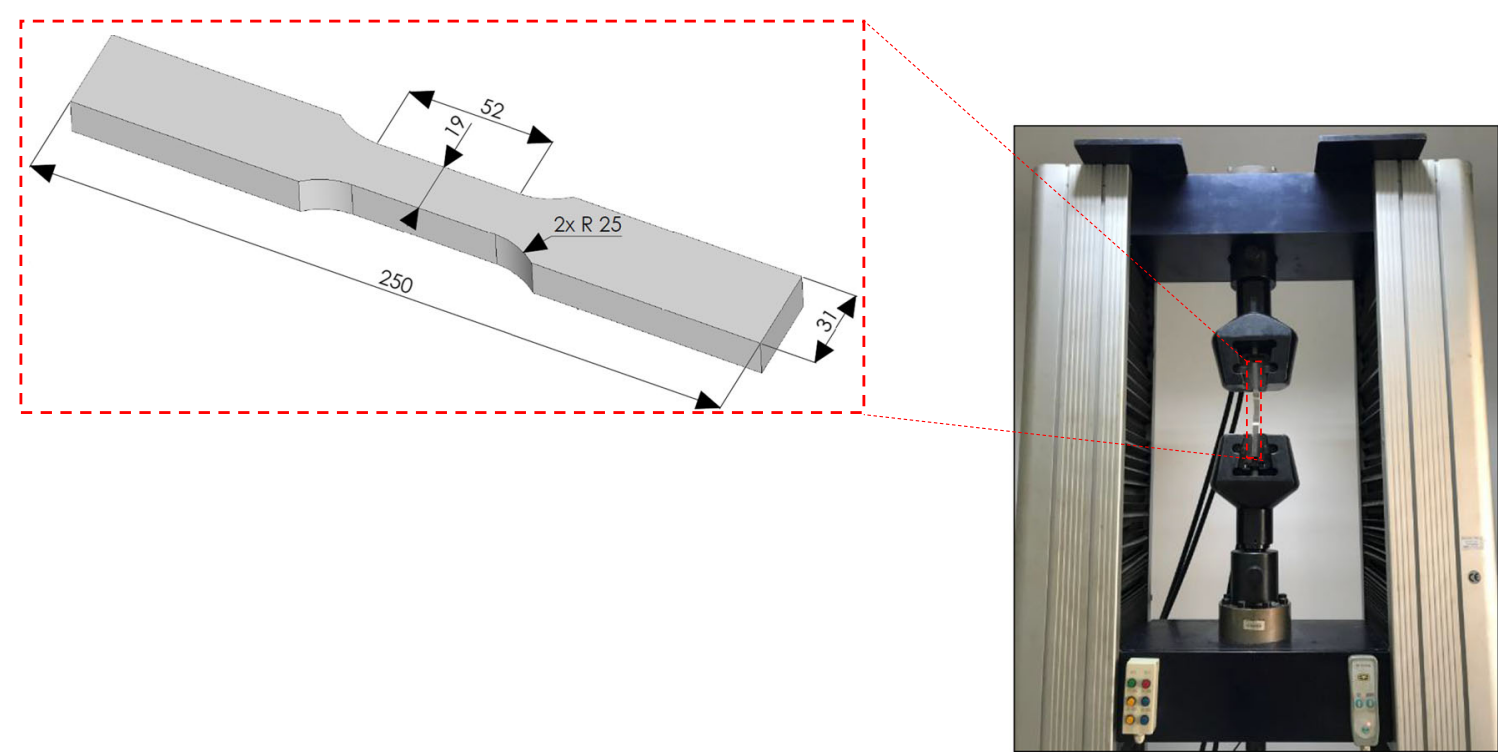

Fig. 5 Forms and dimensions of the tensile test specimens 


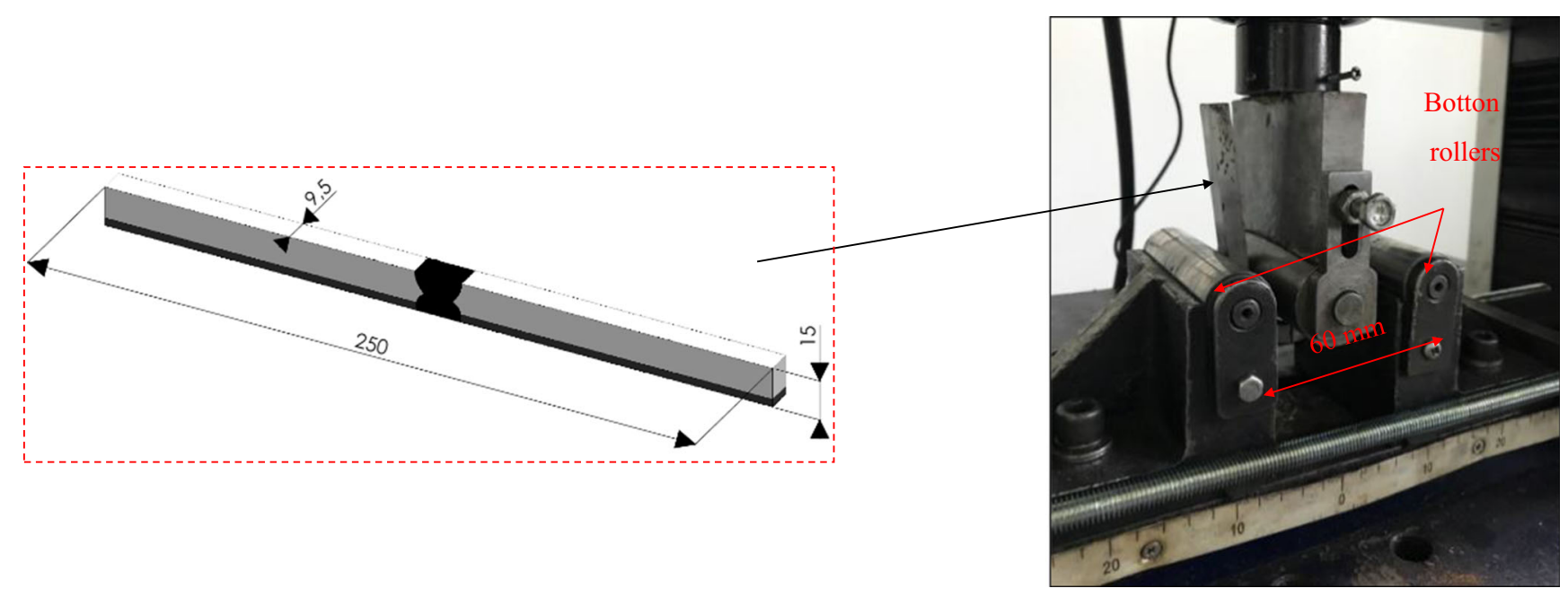

Fig. 6 Forms and dimensions of the side bend test specimens

becomes very complicated because of the reheating of the underlying microstructure. This not only influences the grain size of the welded bead but also can affects its strength. Thus, in order to acquire a good insight of the HAZ, the study of the temperature evolution and cooling rate during the welding process becomes crucial. In this manuscript, three main points were detailed: (i) a thorough investigation of the temperature evolution during the welding of the selected stainless clad steel material was carried out, followed by (ii) a detailed post welding distortion analysis (iii) followed by a study of the tensile and bend mechanical properties of the welded joint. The metallurgical investigation, however, was not detailed in this paper as it is not within the scope of this study.

\subsection{Analysis of welding temperature evolution during welding}

During the experiment, the welding thermal cycle (WTC) of each thermocouple was recorded. Each WTC showed a temperature variation as a function of the welding time. Figure 8 shows the WTCs of root and third welding passes during the SMAW process. This figure shows an abrupt decrease in temperature. This might be the result of either the grinding operations, filler metals switch, or alignment strongbacks removal as indicated in Fig. 8a. In addition, when the heat source moves, the measured temperature at a certain point increases until it reaches a maximum value. As soon as it moves away from this point, it decreases. Moreover, the same figure shows, as expected, that the thermocouples 1, 2, 6, and 7 have the highest temperature peaks compared to the thermocouples 3,4 , and 5 . This fact might be explained by the locations of thermocouples 1,2,6, and 7, which are the closest to the weld bead. This result can be confirmed by the next figure (Fig. 9) where the WTCs along longitudinal direction were recorded. However, since the peak temperature decreases when the source moves away from the weld centerline, the temperature evolution along a transversal direction was studied. Figure 10 shows that WTC of the thermocouple 2 was the first to reach its maximum followed by the other thermocouples respectively. Likewise, the peak temperature of thermocouple 3 is smaller than that of thermocouple 2, and this is representative of the other thermocouples. This is obviously due to the material thermal diffusivity since the heat transmitted through a material by conduction is referred to its thermal conductivity. The findings of our experimental study are in line with those of Murugan et al. [31] who studied the temperature distribution during multi-pass welding of AISI 304. Besides, temperature evolution along thickness was investigated. The peak temperatures of thermocouples 6 and 8 present variations in both phasing and peak temperatures values as illustrated in Fig. 8. In order to understand these variations, thermocouples 6 and 8 WTCs are plotted separately during root, third, and fourth passes as shown in Figs. 11 and 12.

Figure 11a shows that the two peaks are in phase at the root pass. Nevertheless, the peak temperature of thermocouple 6 is higher than that of thermocouple 8 with a small difference in
Fig. 7 Macroscopic cross section of hot-roll cladding steel after welding

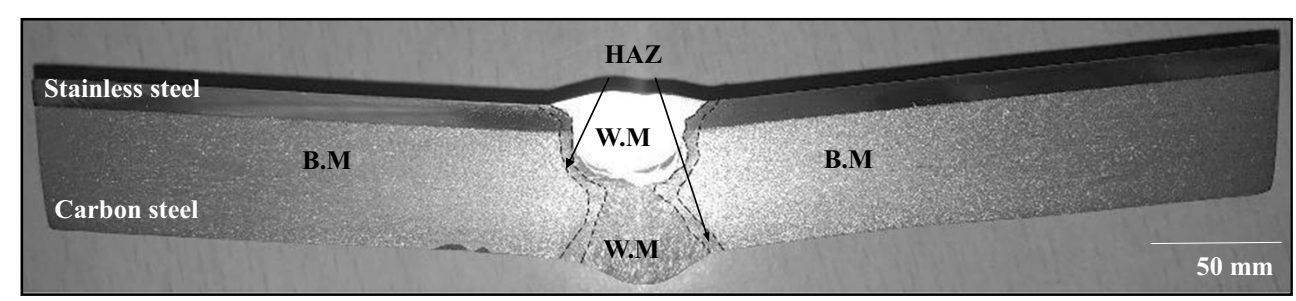



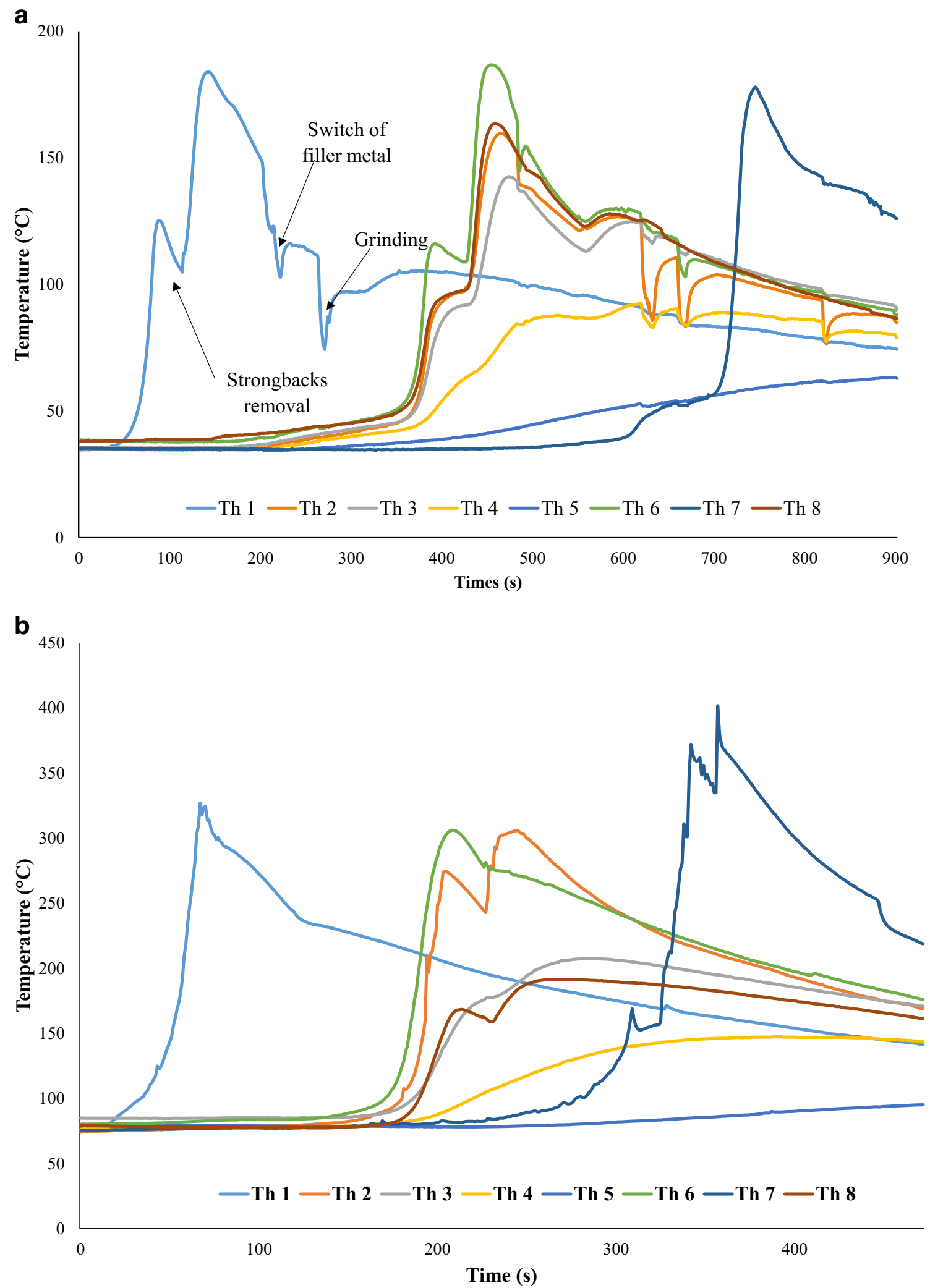

Fig. 8 Welding thermal cycles during SMAW process (a) root pass and (b) cover pass (third pass)

maximal temperatures. This is probably due to the thermal conductivity and thermal diffusivity of the stainless steel. Actually, it should be noted that the thermal conductivity of stainless steel is about $30 \%$ less than that of carbon steel as described in ASM International Handbook Vol.01 [32]. Contrariwise, Fig. 11b shows that the two peaks are not in 


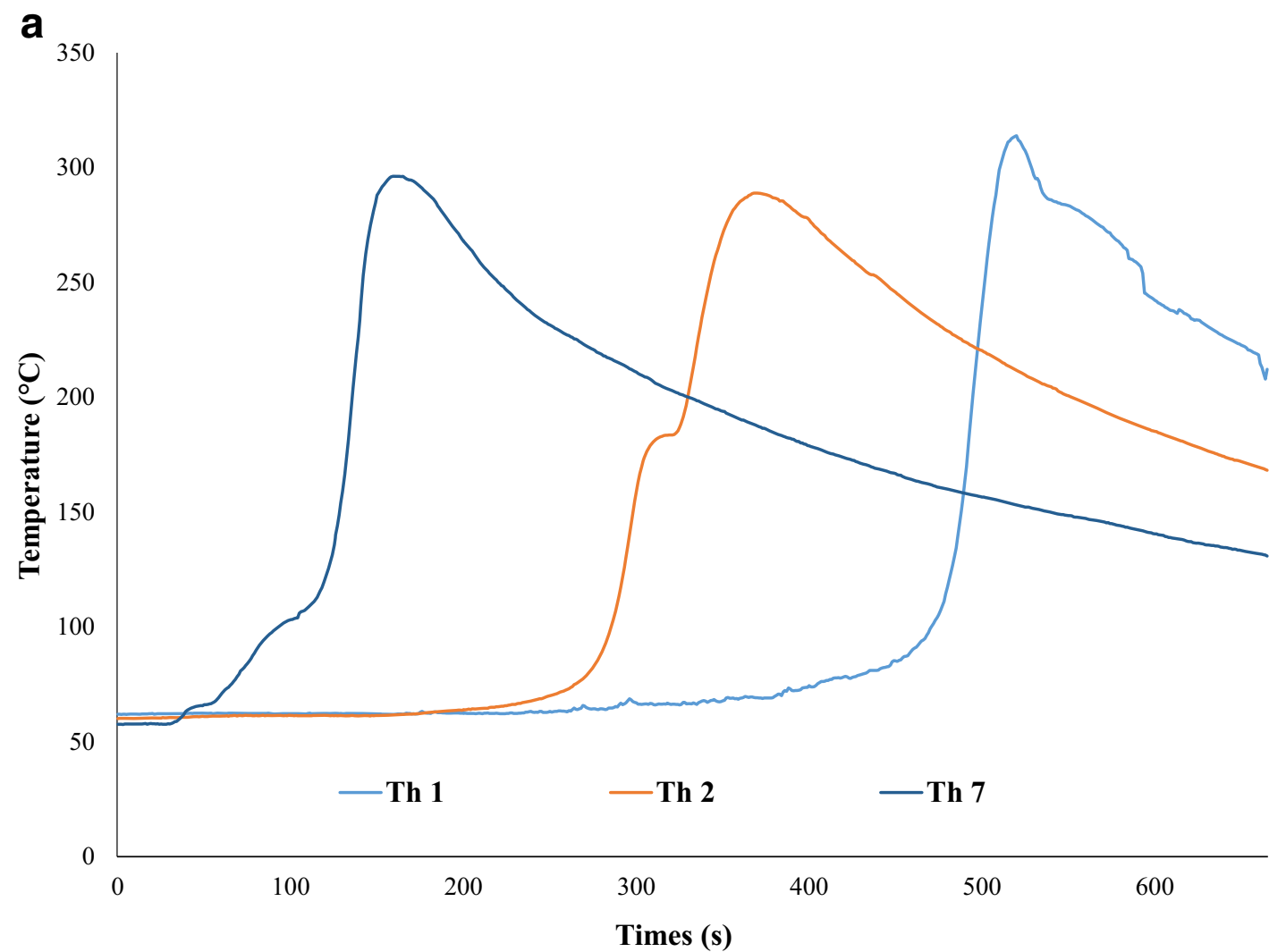

b

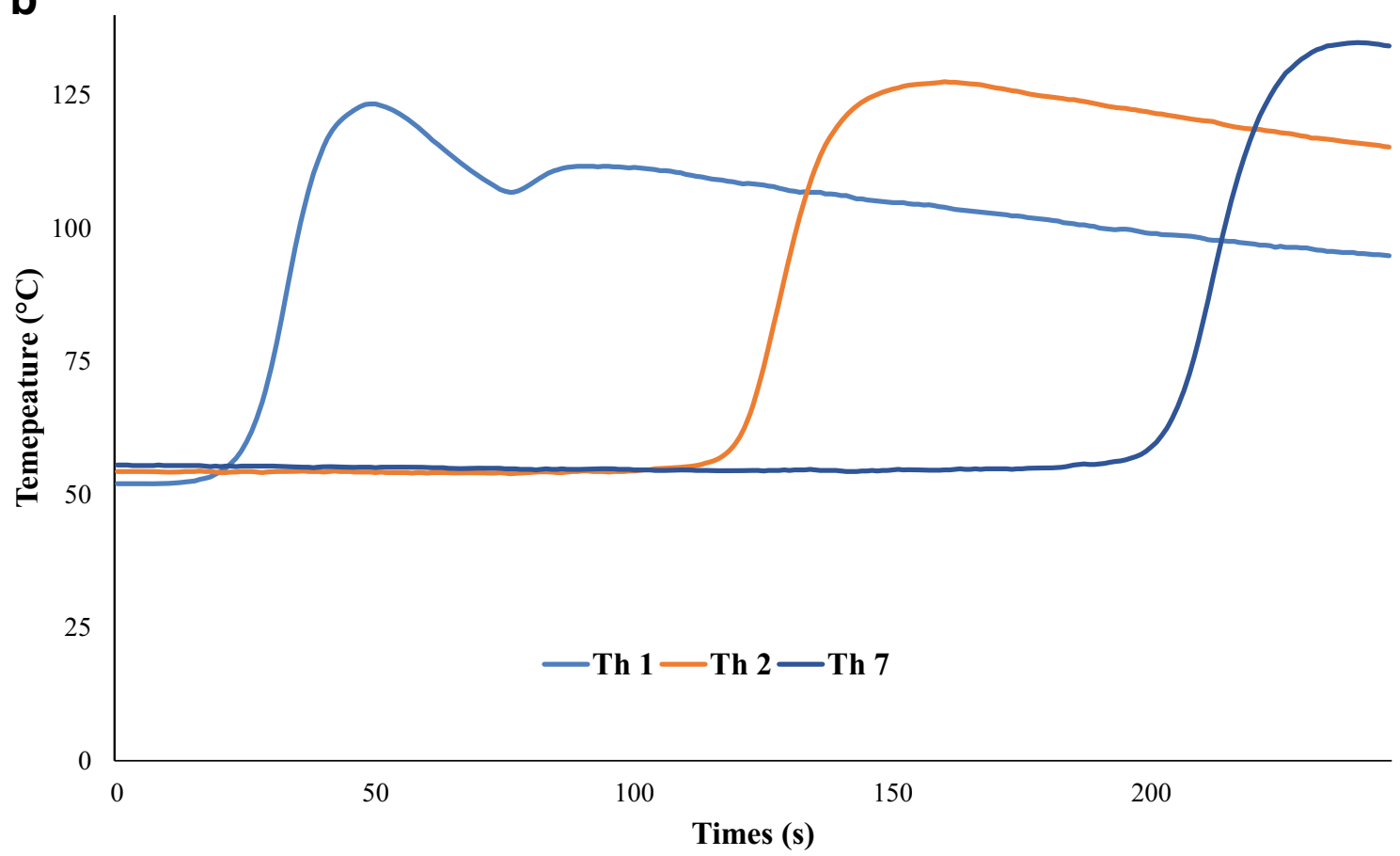

Fig. 9 Longitudinal welding thermal cycles during the SMAW and GTAW processes respectively (a) second pass and (b) sixth pass

phase and that the difference in peaks temperatures during the cover pass is higher than that of the root pass. These differences are probably due not only to the unequal distance between the third welded bead layer and the two thermocouples but also to the thermal conductivity and thermal diffusivity of the bi-material. For a further understanding of the thermal conductivity impact, the WTCs of the same thermocouples during the fourth pass were plotted. Figure 12 shows that, 


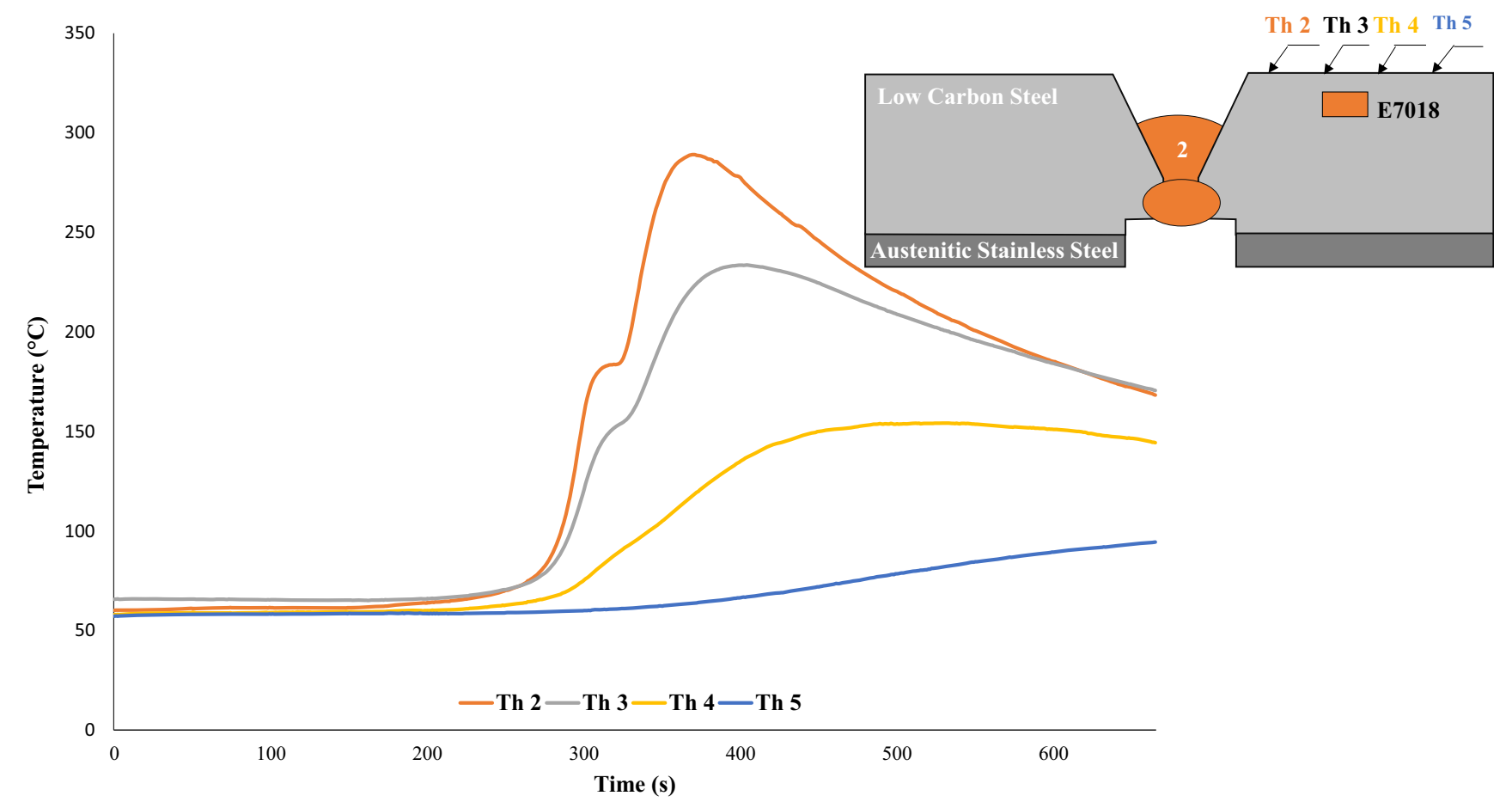

Fig. 10 Transversal welding thermal cycles during the second pass using the SMAW process of thermocouples 2, 3, 4, and 5

despite the small distance between the fourth welded bead layer and thermocouple 8 , the peak temperature in thermocouple 6 is higher than that of thermocouple 8 . This is probably due to the argon used in GTAW process, as well as the thermal conductivity of clad material. Actually, argon has a lower thermal conductivity rate which affects the ability of the gas to transfer the thermal energy.

\subsection{Welding distortion analysis}

Because of the imminent post welding heat effects, some dimensional changes took place. Hence, the main distortions caused by the residual stresses, and which could modify the original shape of the materials, are angular distortion, longitudinal shrinkage, and transversal shrinkage. These distortions are described in the ASM International Handbook Vol.06 [22] and represented schematically in Fig. 13.

The angular distortion and the longitudinal shrinkage are shown in Fig. 14. Indeed, the rise and fall in temperature during welding, as previously shown in Fig. 8, cause a change in volume due to the thermal expansion phenomenon at the fusion zone. Nevertheless, the welded metal tends to contract during the cooling phase until it reaches the room temperature. The free contraction is restricted by the coldest adjacent base metal. Thus, internal stresses are developed within both the weld and the adjacent base metal until the elastic limit is reached. Therefrom, the welded bead deforms and adjusts to the final volume at ambient temperature.
In ordinary cases, it is obvious that angular distortion occurs after each multi-pass welding. A schematic view was provided in order to study the angular distortion during the butt welding process qualitatively. $T^{*}{ }_{0}$ and $T_{\mathrm{h}}^{*}$, in Fig. 14 , are the temperatures on the top and bottom surfaces, respectively. During each pass, the points near the top surface drift towards the weld centerline at a greater extent compared to the points on the bottom surface causing, therefore, a distortion on the top surface. This is due to the high temperature of $T^{*}{ }_{0}$. The evolution of the angular distortion value depends on a number of factors such as HI [33]; number of passes [34]; welding sequence and direction [35]; and bead shape [36] among others.

In our case study, the angular distortion ( $\beta$ ), with a value of $9.1^{\circ} \mathrm{C}$, is observed on the thin clad layer side (Fig. 15). This angular distortion is calculated as shown in Fig. 16 and described in the work of Manurung et al. [37] using the following relationship (Eq. (3)):

$\beta=\sin ^{-1}(\mathrm{dz} / L)$

where $\beta$ is the angular distortion, $d Z$ is the displacement in $z$ direction, and $L$ is the distance.

In fact, the welding of the test coupon during passes number 1,2 , and 3 is similar to the ordinary cases. Indeed, the peak temperature of Th6 (corresponding to $T^{*}{ }_{0}$ ) is greater than Th8 (corresponding to $T^{*}{ }_{h}$ ) as already shown in Fig 11 . Consequently, an angular distortion occurred on the carbon steel side. However, during the fourth pass, the temperature 

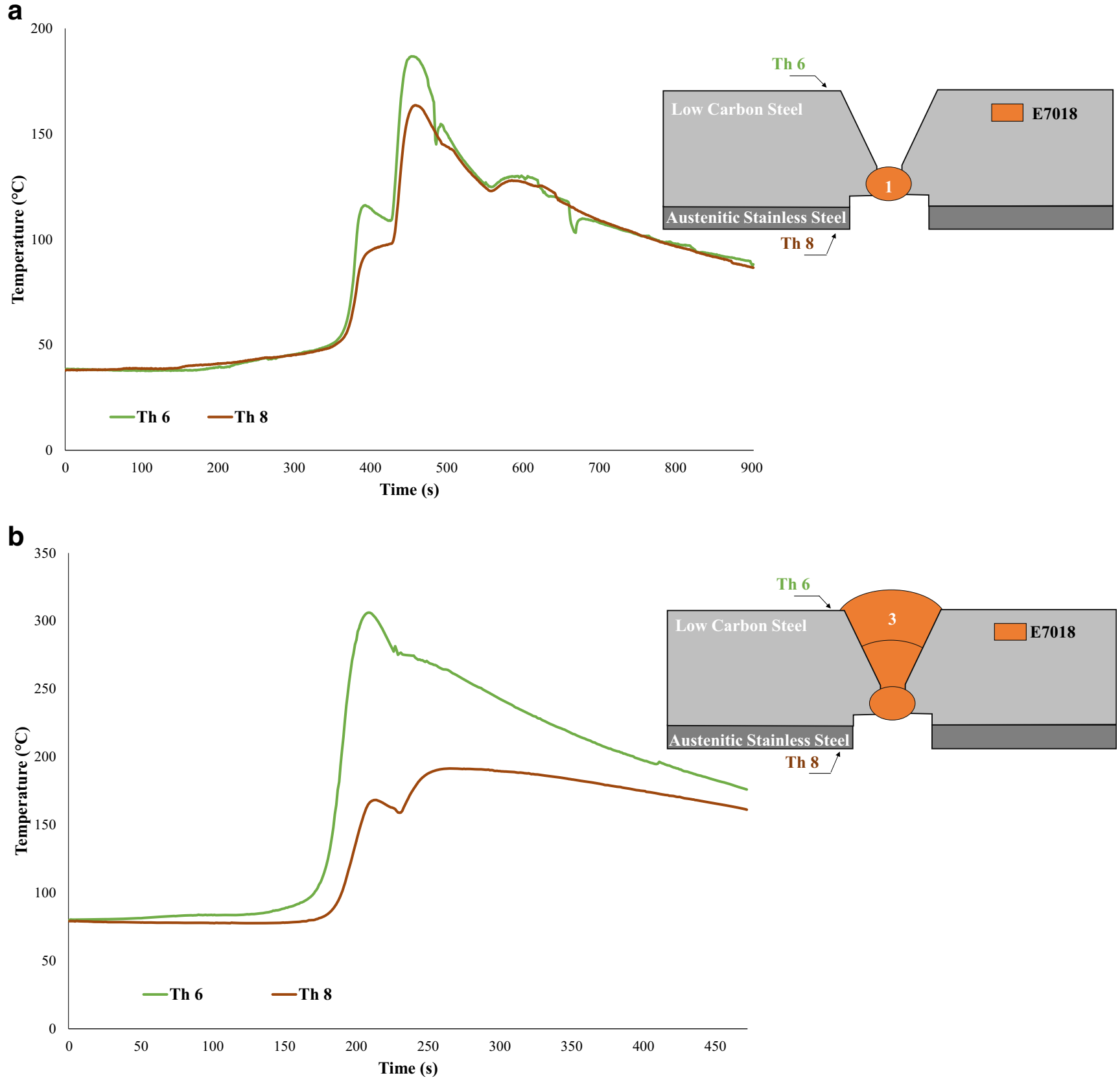

Fig. 11 Welding thermal cycles of thermocouples 6 and 8 during the SMAW process (a) root pass and (b) cover pass

gap between peak temperatures measured by Th6 and Th8, shown in Fig 12, decreases compared to their values observed in Fig 11. From the fifth pass, the peak temperature of $\mathrm{Th} 8$ has become highest and therefore the angular distortion adjusts, to the stainless steel side. Figure 17 illustrates the Th6 and Th8 WTCs during the fourth and fifth passes, whereas Fig. 18 represents a schematic angular distortion evolution during the welding.

The angular distortion on the stainless steel side can be due to several factors. Firstly, the thermal expansion coefficient may be the origin of the observed angular distortion.
Actually, as reported in the ASM International Handbook Vol.06 [22], the stainless steel thermal expansion coefficient is greater than that of the carbon steel. This result may be confirmed by the empirical relation (Eq. (3)) [34]:

$\beta=2 \cdot \gamma \cdot T \cdot \tan (\theta / 2)$

where $\boldsymbol{T}$ is temperature of the material softening, $\gamma$ is the thermal expansion coefficient, and $\theta$ is the groove angle. This relationship affirms that the higher the expansion coefficient is, the more the angular distortion increases. 


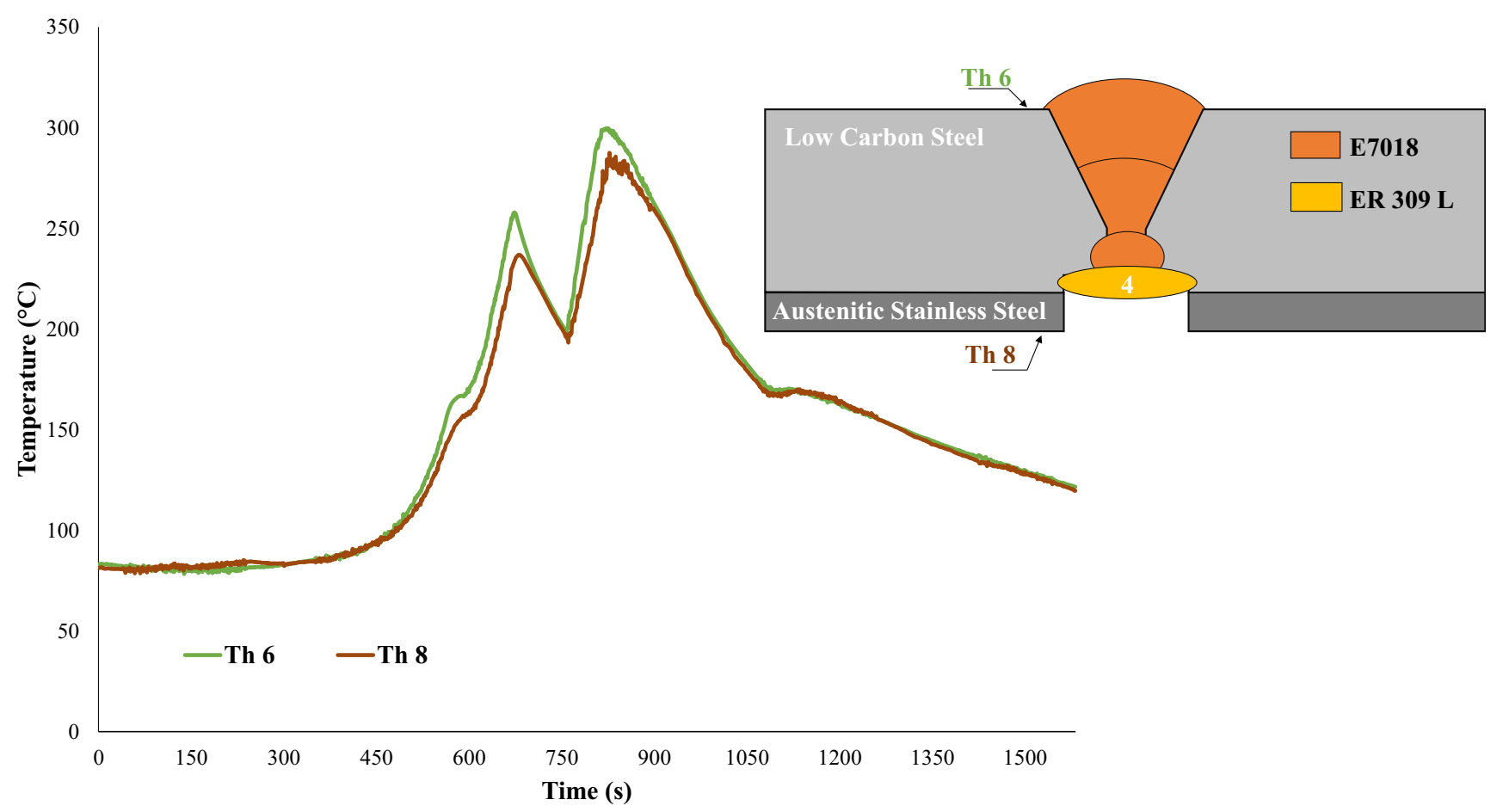

Fig. 12 Welding thermal cycles of thermocouples 6 and 8 during the fourth pass using the GTAW process

Secondly, the required heat to melt the clad layer, at equal volume, is higher than that required to melt the carbon steel resulting in greater the residual stresses on the stainless steel side.

Moreover, the volume of the molten zone (deposed metal ER309L+ER316L+ great portion of the root pass) on the stainless steel side, shown in Fig. 19, is greater than that of the molten zone (passes number 2 and 3 using

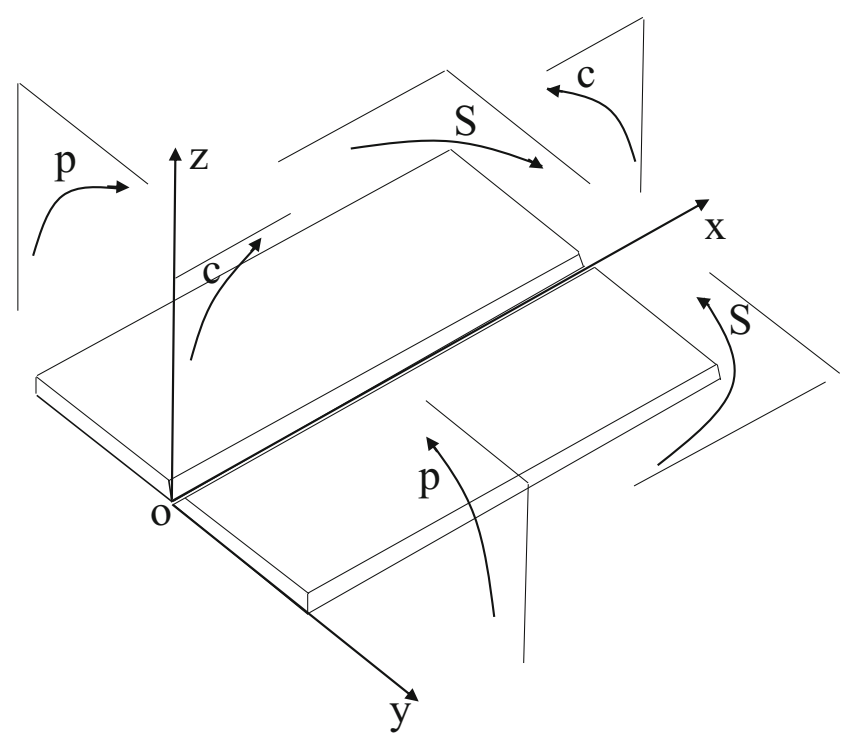

Fig. 13 Main deformation directions, (oy) angular distortion, (ox) longitudinal shrinkage (oz) transversal shrinkage
E7018) on the carbon steel side with a proportional $V_{2} \approx 1,2 \times V_{1}$. Since the volume of $V_{2}$ is greater than that of $V_{1}$, the residual stress seems to be greater on stainless steel side generating the observed angular distortion on the clad layer side.

Furthermore, the number of passes on the stainless steel side can be at the origin of the observed result. Indeed, compared to the carbon steel side (three passes), an excessive heat was applied on the clad layer side due to the number of passes (six passes) ending up in an angular distortion on the stainless steel side.

\subsection{Mechanical properties of the welded joint}

\subsubsection{Tensile test}

The transverse tensile strengths of the specimens have been evaluated. The typical obtained tensile curves are shown in Fig. 20. The mechanical properties, namely, tensile strength, yield strength, and elongation, are presented in Table 3.

One of the significant outcomes of these tensile tests is that the two specimens were fractured out of the welded joint area (i.e., failure is localized in the BM far about $4 \mathrm{~cm}$ away from the welded joint). Additionally, it is observed from the Table 3 that the tensile properties of the welded clad material are higher than that of the tensile properties of the unwelded clad material. 
Fig. 14 Schematic representation of the temperature flux during welding

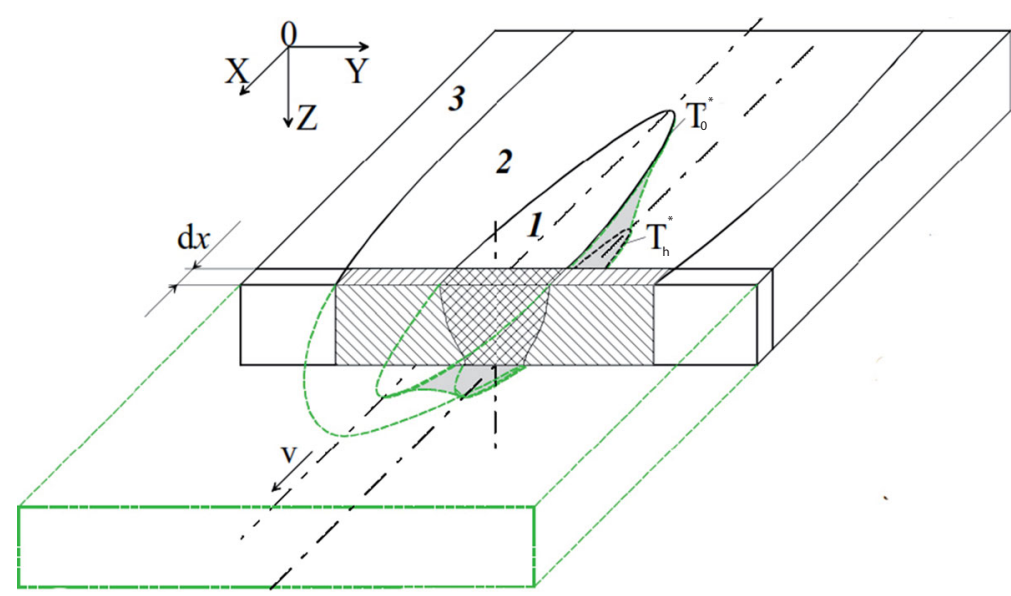

Austenitic stainless steel side

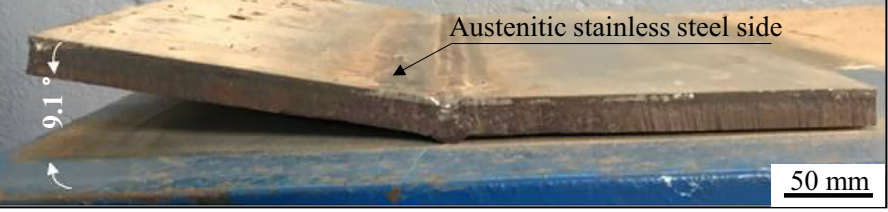

a

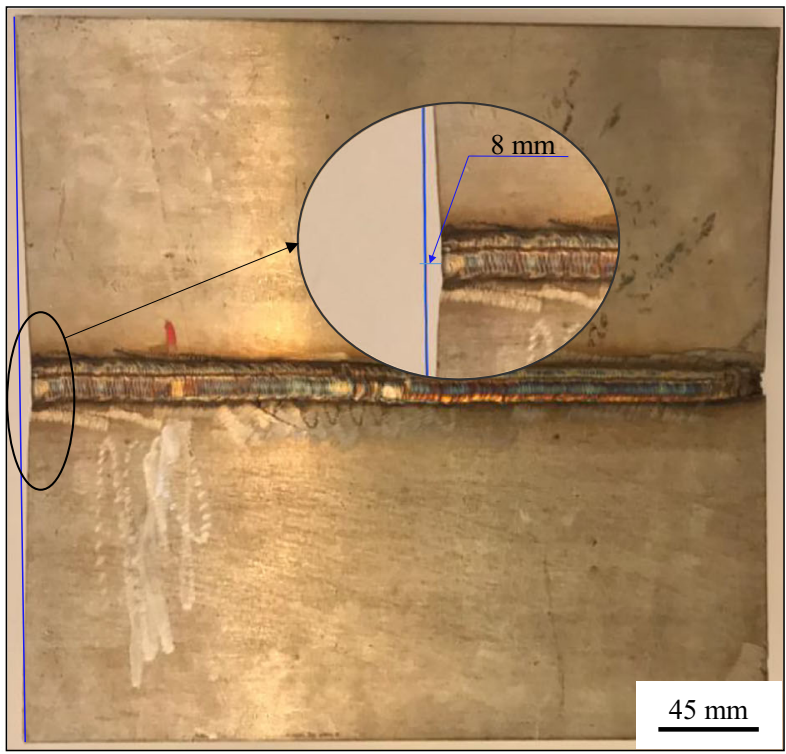

b

Fig. 15 The obtained residual stress effect after the multi-pass welding, (a) angular distortion and (b) longitudinal shrinkage

Fig. 16 Displacement measurement to calculate the angular distortion
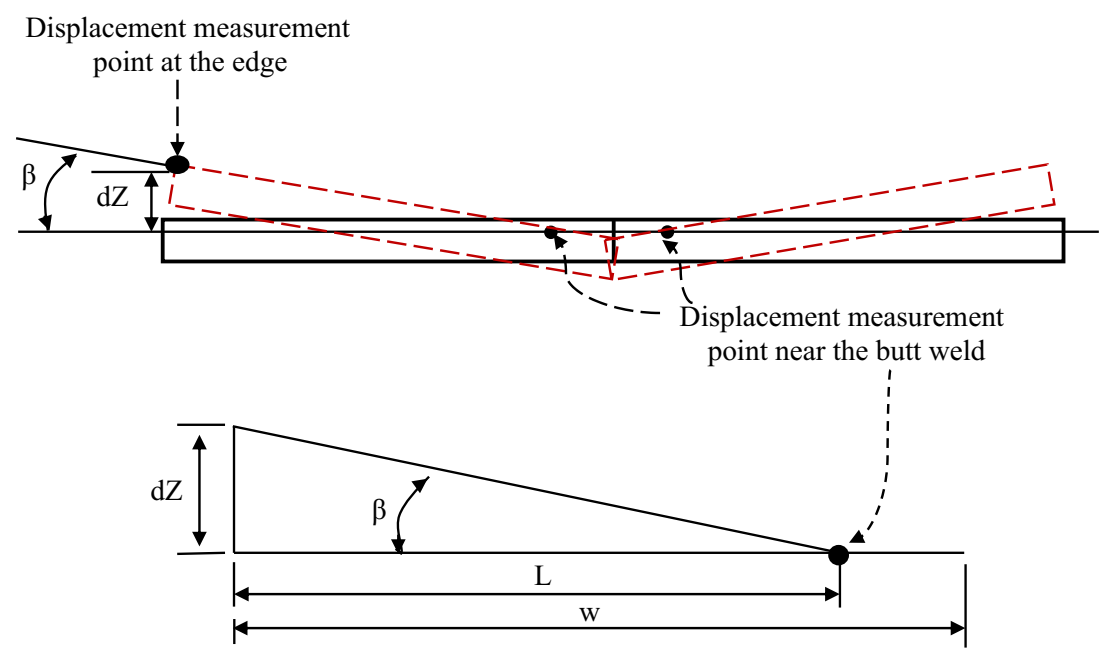


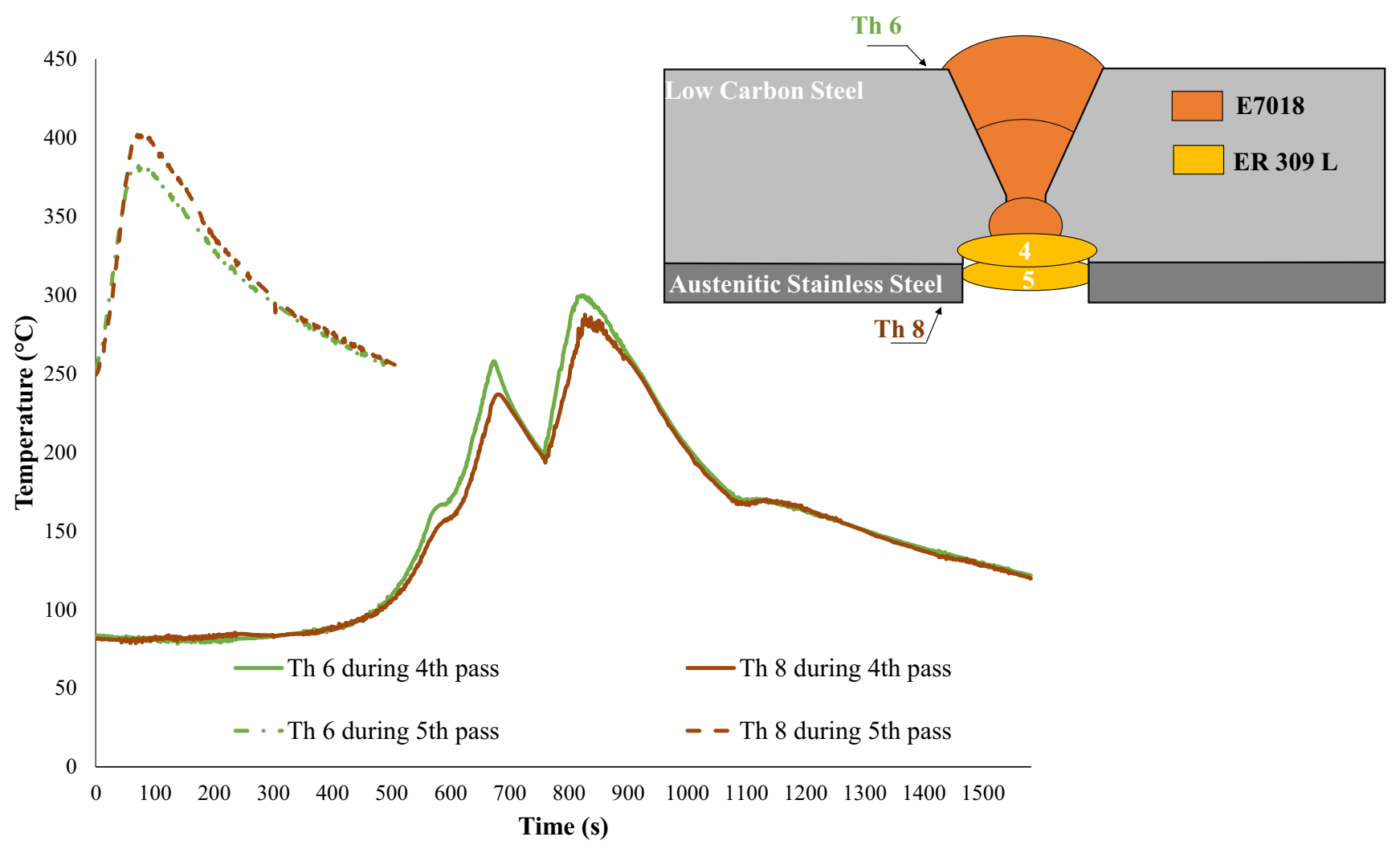

Fig. 17 Welding thermal cycles of Th6 and Th8 during fourth and fifth passes, respectively

These results show that the WM is more resistant than the base clad material, which confirm the ASME IX requirement [20]. Figure 21 shows a fractograph of the broken specimen after the tensile test. The fractograph reveals a mixed shear dimple. The dimples, which correspond to the micro-voids characteristic of monotonic ductile fracture, appear on the most of the fractured surface. Although the shear fracture occurs along the shear fracture direction at an angle near $45^{\circ}$ to the tensile axis, the shear fracture mode is particularly dominant on the clad stainless steel and on the two carbon steel corners (Fig. 21).

Fig. 18 Schematic representation of angular distortion evolution during passes on carbon steel and clad layer sides

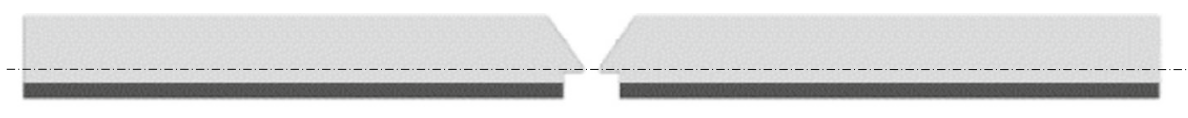

Initial Stage

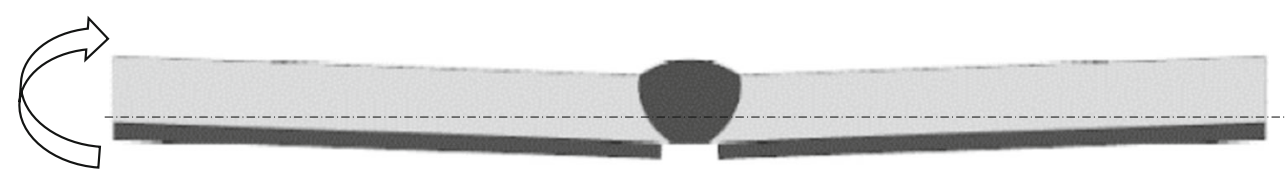

Sense of the angular distortion on the welded plates after the deposition of E7018 (passes 1, 2,3)

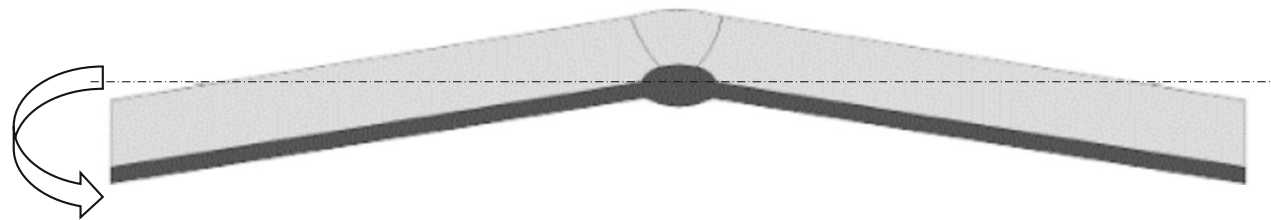

Sense of the angular distortion on the welded plates at the end of the weld process (after passes $4,5,6,7,8,9$ ) 
Fig. 19 Surfaces' measurement of deposited metal

Fig. 20 Specimens' tensile curves

\subsubsection{Bending appearance}

Bending tests were applied on the four side bend specimens. Figure 22 shows the typical macrostructure of the samples

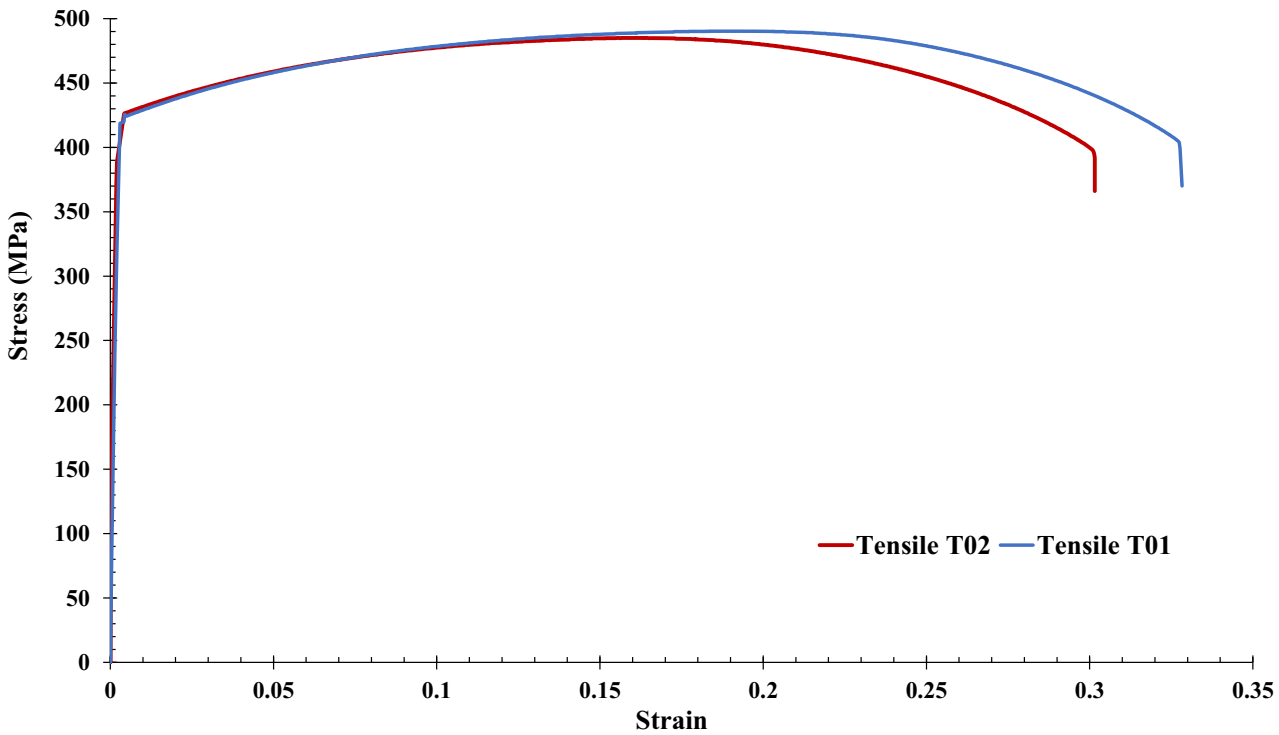

after the bending test. The result indicates that no separations, fractures, or tearing were observed on all bent surfaces. These findings are completely in compliance with the industrial code ASME IX [20]. However, a bulging phenomenon appears in the weld area after bending. This phenomenon can be caused
Table 3 Monotonic tensile properties at room temperature

\begin{tabular}{lll}
\hline & Welded clad material & Unwelded clad material \\
\hline Tensile strength Rm & $487 \pm 2.8$ & $438 \mathrm{MPa}$ \\
Yield Strength Re & $423 \pm 2.5$ & $418 \mathrm{MPa}$ \\
Elongation A (\%) & $31.4 \pm 1.4$ & 30 \\
\hline
\end{tabular}



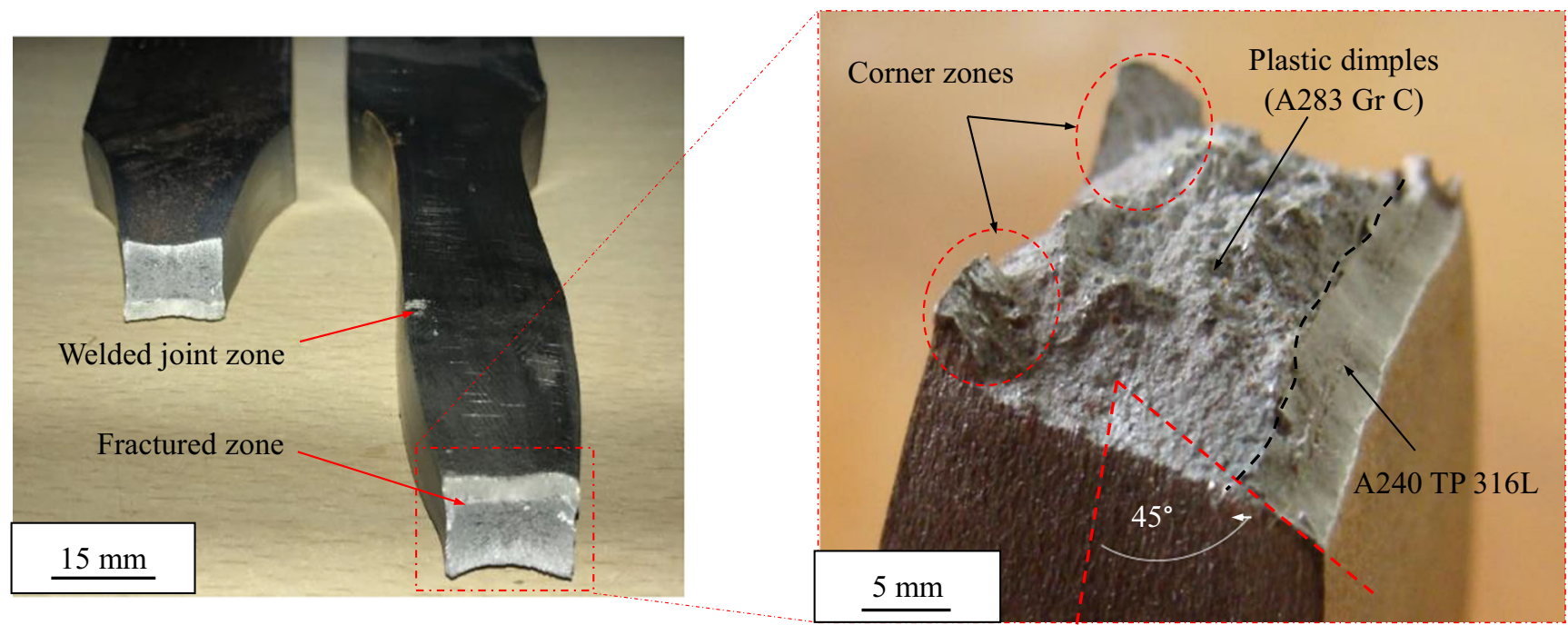

Fig. 21 Surface fracture after the tensile test

by the presence of a local hardening zone (LHZ) with low plasticity. Li et al [38] reported in their work that the LHZ, which was found on the outer surfaces of the side bend specimens and which underwent tension stress state, is bulged due to its high hardness and low plasticity. These authors also affirm that the LHZ was formed due to the presence of a martensitic structure. Dhib et al. [9] considered that the LHZ appeared in the transition phase when they used the filler metal 309L. They also reported that the highest value of the microhardness measured on the transition phase 309L can reach $300 \mathrm{HV}$.

\section{Conclusion}

In this manuscript, the effect of the multi-pass welding process on the stainless steel clad plate joint was investigated. The temperature distribution along longitudinal, transversal, and thickness directions was studied during the welding process using several thermocouples fixed on the plates. Then, the longitudinal shrinkage and the angular distortion generated during the welding process by the effect of the heat fluxes were examined after cooling. An angular distortion of $9.1^{\circ}$ and a longitudinal shrinkage of $8 \mathrm{~mm}$ were, respectively,

Fig. 22 Bent surface after side bend test

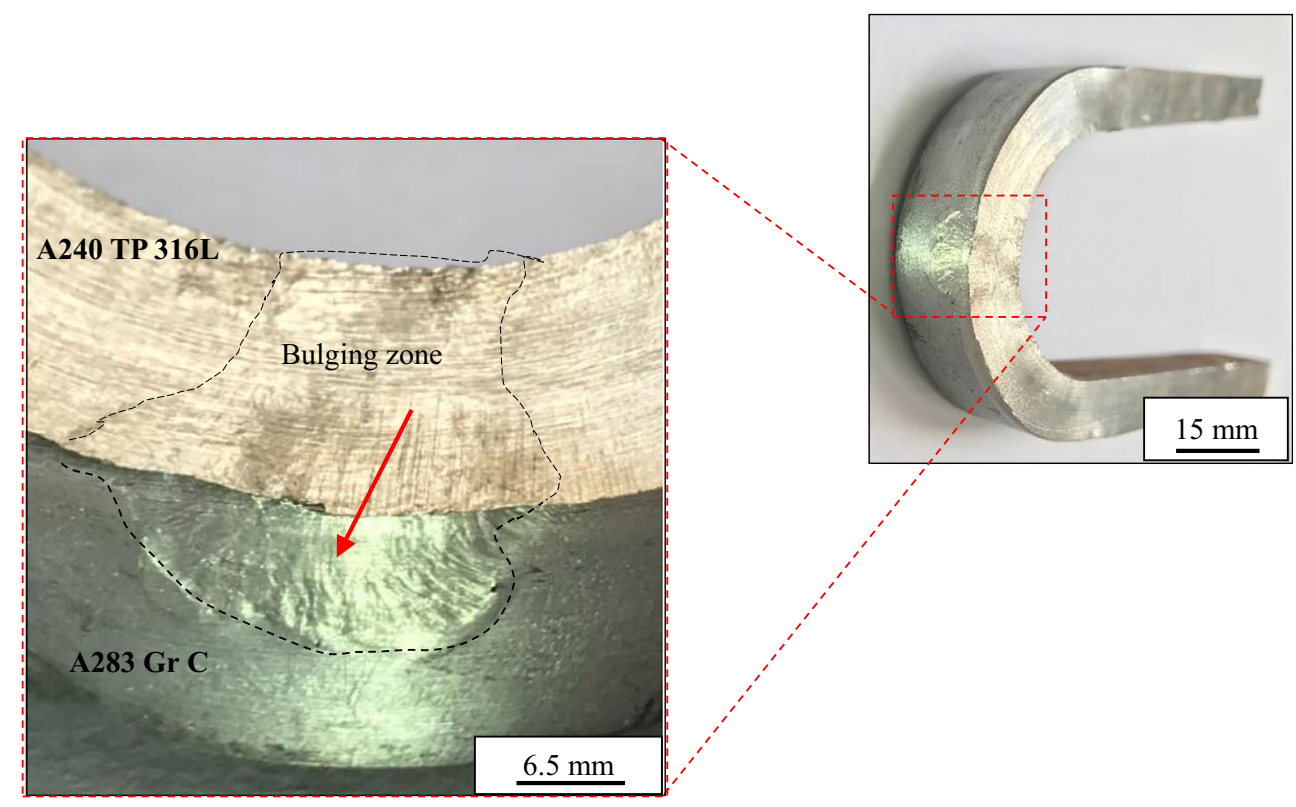


measured on the welded coupon. These distortions could have been generated by the residual stresses during the welding process. Owing to the great heat concentration provided during the welding process, the areas near the weld centerline underwent severe thermal cycles, thereby generating inhomogeneous plastic deformation and residual stresses on the welded coupon that change in accordance with the welding pass number. Results show that despite the large thickness of the substrate (carbon steel), the angular distortion obtained after the welding process occurred on the thin clad layer side. This phenomenon can be attributed to:

(i). The higher thermal expansion of the stainless steel clad layer compared to the substrate made by carbon steel.

(ii). The required heat degree to melt the austenitic stainless steel which is, at equal volume, higher than that needed to melt the substrate material.

(iii). The amount of filler metal deposited on the clad layer side is greater than that on the substrate side.

(iv). The number of passes used on the clad layer which is greater than that used on the substrate.

In order to evaluate the reliability of the stainless steel clad plate joint after the welding process, tensile and bend mechanical tests were carried out using different specimens extracted from the welded coupon. The tensile tests results indicate that the specimens were fractured at the base metal far about $4 \mathrm{~cm}$ away from the welded joint. In addition, the examination of the fractured surfaces revealed the presence of dimples that characterize monotonic ductile fracture. The examination of the bent specimen surfaces after bending revealed no sign of crack or tear. However, a bulging phenomenon was observed on the welded joint bent surfaces that proves the presence of a local hardening zone with a low plasticity.

In light of the reached outcomes, numerical simulations of the studied multi-pass welding process of the stainless clad steel plates may be a useful tool to predict the values of the residual stresses and distortion of the welded joint not only after the weld cooling but also between the different weld passes. The recorded temperature during the process may serve as a database for the numerical model validation.

Acknowledgments The authors would like to thank SOCOMENIN Company for their support. They equally would like to thank Mr. M.T. Hbaieb and A. Badri, staff engineers at SOCOMENIN Company, for their knowledgeable help and support.

\section{Declarations}

Ethical approval Not applicable

Consent to participate not applicable Not applicable
Conflict of interest The authors declare that they have no conflict of interest

\section{References}

1. Kaya Y, Kahraman N (2013) An investigation into the explosive welding/cladding of Grade A ship steel/AISI 316L austenitic stainless steel. Mater Des (1980-2015):52, 367372. https://doi.org/10. 1016/j.matdes.2013.05.033

2. Venkateswara Rao N, Madhusudhan Reddy G, Nagarjuna S (2011) Weld overlay cladding of high strength low alloy steel with austenitic stainless steel - structure and properties. Mater Des 32(4):24962506. https://doi.org/10.1016/j.matdes.2010.10.026

3. Khodadad Motarjemi A, Koçak M, Ventzke V (2002) Mechanical and fracture characterization of a bi-material steel plate. Int J Press Vessel Pip 79(3):181-191. https://doi.org/10.1016/S03080161(02)00012-1

4. Ganesh P, Moitra A, Tiwari P, Sathyanarayanan S, Kumar H, Rai SK et al (2010) Fracture behavior of laser-clad joint of Stellite 21 on AISI 316L stainless steel. Mater Sci Eng A 527(16-17):37483756. https://doi.org/10.1016/j.msea.2010.03.017

5. Flahaut P (1995) Caractérisation et comportement mécanique de placages bimétalliques. Doctoral dissertation, Lille 1. https://orinuxeo.univ-lille1.fr/nuxeo/site/esupversions/edaf9d60-01c6-4814b6c0-7902697c9fc0

6. Akramifard HR, Mirzadeh H, Parsa MH (2014) Cladding of aluminum on AISI 304L stainless steel by cold roll bonding: mechanism, microstructure, and mechanical properties. Mater Sci Eng A 613: 232-239. https://doi.org/10.1016/j.msea.2014.06.109

7. Azzeddine H, Tirsatine K, Baudin T, Helbert A-L, Brisset F, Bradai D (2014) Texture evolution of an Fe-Ni alloy sheet produced by cross accumulative roll bonding. Mater Charact 97:140-149. https://doi.org/10.1016/j.matchar.2014.09.009

8. Jing Y, Qin Y, Zang X, Li Y (2014) The bonding properties and interfacial morphologies of clad plate prepared by multiple passes hot rolling in a protective atmosphere. J Mater Process Technol 214(8):1686-1695. https://doi.org/10.1016/j.jmatprotec.2014.03. 019

9. Dhib Z, Guermazi N, Gaspérini M, Haddar N (2016) Cladding of low-carbon steel to austenitic stainless steel by hot-roll bonding: microstructure and mechanical properties before and after welding. Mater Sci Eng A 656:130-141. https://doi.org/10.1016/j.msea. 2015.12.088

10. Qin G, Tang Y, Zhang B, Lin S, Geng P (2020) Microstructures and mechanical properties of stainless steel clad plate joint with diverse filler metals. J Mater Res Technol. https://doi.org/10.1016/j.jmrt. 2019.12.083

11. An Q, Fan KY, Ge YF, Liu BX, Liu YC, Wang S et al (2020) Microstructure and mechanical properties of stainless steel clad plate joints produced by TIG and MAG hybrid welding. J Adhes Sci Technol 34(6):670-685. https://doi.org/10.1080/01694243. 2019.1677087

12. Qiu T, Wu BX, Chen QY, Chen WJ (2013) Analysis on welded joint properties of stainless clad steel plates. Dianhanji/ Electric Welding Machine 43(4):83-87

13. Missori S, Murdolo F, Sili A (2004) Single-pass laser beam welding of clad steel plate. Weld J https://art.torvergata.it/retrieve/handle/ 2108/60687/101757/WJ-02-2004-MISSORI-s.pdf

14. Moore JP (1954) Maintaining the corrosion resistance of welded stainless steel. Anti-Corros Methods Mater 1(4):92-112. https://doi. org/10.1108/eb018925

15. Jiang W, Liu Z, Gong JM, Tu ST (2010) Numerical simulation to study the effect of repair width on residual stresses of a stainless 
steel clad plate. Int J Press Vessel Pip 87(8):457-463. https://doi. org/10.1016/j.ijpvp.2010.06.003

16. Hajiannia I, Shamanian M, Kasiri M (2013) Microstructure and mechanical properties of AISI 347 stainless steel/A335 low alloy steel dissimilar joint produced by gas tungsten arc welding. Mater Des 50:566-573. https://doi.org/10.1016/j.matdes.2013.03.029

17. Wang SG, Dong GP, Ma QH (2009) Welding of duplex stainless steel composite plate: influence on microstructural development. Mater Manuf Process 24(12):1383-1388. https://doi.org/10.1080/ 10426910902997456

18. Park J-W, Lee C-K (2013) Mechanical properties and sensitization on clad steel welding design. Int J Precis Eng Manuf 14(11):19391945. https://doi.org/10.1007/s12541-013-0263-z

19. Itsuro $T$, Isamu $O$, Isamu $T$, Izumi $O$ Welding distortion of austenitic stainless clad steel. J Jpn Weld Soc. https://doi.org/10.2207/ qijws 1943.43.684

20. ASME IX (2017) ASME boiler and pressure vessel code, section IX: welding and brazing qualifications. An International Code, New York

21. Kumar KVS, Gejendhiran S, Prasath M (2014) Comparative investigation of mechanical properties in GMAW/GTAW for various shielding gas compositions. Mater Manuf Process 29(8):9961003. https://doi.org/10.1080/10426914.2014.901527

22. Ferjutz K, Joseph R D (1993) ASM Handbook Welding, Brazing and Soldering, vol. 6. ASM International, Materials Park

23. ANSI/AWS B2.1-1-016-94R (1993) Standard welding procedure specification (WPS) for shielded metal arc welding of carbon steel (M-1/P-1/S-1, group 1 or 2) 1/8 through 1 1/2 inch thick, E7018 AsWelded or PWHT condition, p25

24. ANSI/AWS B2.1-8-024 (2001) Standard welding procedure specification (WPS) for Gas Tungsten Arc Welding of Austenitic Stainless steel (M-8/P-8/S-8, group 1) 1/16 through $11 / 2$ inch thick, ER3XX As-Welded Condition. Primarily Plate and Structural Applications, USA

25. Lee Y, Bandari Y, Nandwana P, Gibson B, Richardson B, Simunovic S (2019) Effect of interlayer cooling time, constraint and tool path strategy on deformation of large components made by laser metal deposition with wire. Appl Sci 9(23):5115. https:// doi.org/10.3390/app9235115

26. Bandari YK, Lee Y, Nandwana P, Richardson BS, Adediran AI, Love LJ, Gaul KT (2018) Effect of inter-layer cooling time on distortion and mechanical properties in metal additive manufacturing (AM). Oak Ridge National Lab.(ORNL), Oak Ridge https:// www.osti.gov/servlets/purl/1474452

27. Fessler JR, Merz R, Nickel AH, Prinz FB, Weiss LE (1996) Laser deposition of metals for shape deposition manufacturing. In 1996 International Solid Freeform Fabrication Symposium. https:// repositories.lib.utexas.edu/bitstream/handle/2152/69928/1996-15Fessler.pdf?sequence $=2 \&$ isAllowed=y

28. American Petroleum Institute Recommended Practice, API RP 582 (2016) "Welding Guidelines for the Chemical, Oil, and Gas Industries"

29. ASME section VIII, Division 1 (2017) ASME Boiler and Pressure Vessel Code, Rules for Construction of Pressure Vessels

30. ASTM Committee E-20 on Temperature Measurement, \& ASTM Committee E-20 on Temperature Measurement. Subcommittee E20. 04 on Thermocouples (1974) Manual on the use of thermocouples in temperature measurement (Vol. 470). ASTM International

31. Murugan S, Kumar P, Raj B, Bose MS (1998) Temperature distribution during multipass welding of plates. Int J Press Vessel Pip 75(12):891-905. https://doi.org/10.1016/S0308-0161(98)00094-5

32. ASM International (1990) ASM Handbook. Properties and selection: irons steels and high performance alloys. Vol.01, 10th Edition, p.1063, ${ }^{3 \text { rd }}$ Edition, USA

33. Murugan VV, Gunaraj V (2005) Effects of process parameters on angular distortion of gas metal arc welded structural steel plates. Weld J 11:165-171 https://app.aws.org/wj/supplement/WJ_2005 11_s165.pdf

34. de Oliveira Silva M, de Araújo DB, Souza D, de Freitas Teixeira PR (2015) The effect of the number of welding passes in the angular distortion of 3041 steel plates using gmaw. https://doi.org/10.20906/ CPS/COB-2015-1123

35. Seyyedian Choobi M, Haghpanahi M, Sedighi M (2011) Effect of welding sequence and direction on angular distortions in buttwelded plates. J Strain Anal Eng Des 47(1):46-54. https://doi.org/ 10.1177/0309324711425887

36. Chiumenti M, Cervera M, Salmi A, Agelet de Saracibar C, Dialami N, Matsui K (2010) Finite element modeling of multi-pass welding and shaped metal deposition processes. Comput Methods Appl Mech Eng 199(37-40):2343-2359. https://doi.org/10.1016/j.cma. 2010.02.018

37. Manurung YHP, Lidam RN, Rahim MR, Zakaria MY, Redza MR, Sulaiman MS et al (2013) Welding distortion analysis of multipass joint combination with different sequences using 3D FEM and experiment. Int J Press Vessel Pip 111-112:89-98. https://doi.org/10. 1016/j.ijpvp.2013.05.002

38. Li C, Qin G, Tang Y, Zhang B, Lin S, Geng P (2020) Microstructures and mechanical properties of stainless steel clad plate joint with diverse filler metals. J Mater Res Technol. https:// doi.org/10.1016/j.jmrt.2019.12.083

Publisher's note Springer Nature remains neutral with regard to jurisdictional claims in published maps and institutional affiliations. 